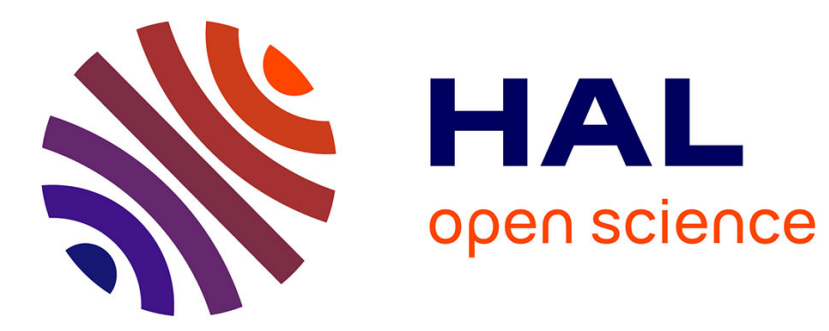

\title{
Three-dimensional turbulence-resolving modeling of the Venusian cloud layer and induced gravity waves. Inclusion of complete radiative transfer and wind shear
}

\author{
M. Lefèvre, Sébastien Lebonnois, A. Spiga
}

\section{- To cite this version:}

M. Lefèvre, Sébastien Lebonnois, A. Spiga. Three-dimensional turbulence-resolving modeling of the Venusian cloud layer and induced gravity waves. Inclusion of complete radiative transfer and wind shear. Journal of Geophysical Research. Planets, 2018, 123 (10), pp.2773-2789. 10.1029/2018JE005679 . hal-01980130

\section{HAL Id: hal-01980130 \\ https: / hal.sorbonne-universite.fr/hal-01980130}

Submitted on 14 Jan 2019

HAL is a multi-disciplinary open access archive for the deposit and dissemination of scientific research documents, whether they are published or not. The documents may come from teaching and research institutions in France or abroad, or from public or private research centers.
L'archive ouverte pluridisciplinaire HAL, est destinée au dépôt et à la diffusion de documents scientifiques de niveau recherche, publiés ou non, émanant des établissements d'enseignement et de recherche français ou étrangers, des laboratoires publics ou privés. 


\title{
Three-dimensional turbulence-resolving modeling of the Venusian cloud layer and induced gravity waves. Inclusion of complete radiative transfer and wind shear
}

\author{
Maxence Lef'evre (maxence.lefevre@lmd.jussieu.fr) ${ }^{1}$, Sébastien Lebonnois ${ }^{1}$, and Aymeric
}

$$
\text { Spiga }{ }^{1,2}
$$

\author{
${ }^{1}$ Laboratoire de Météorologie Dynamique (LMD/IPSL), Sorbonne Université, Centre National \\ de la Recherche Scientifique, École Polytechnique, École Normale Supérieure, Paris, France \\ ${ }^{2}$ Institut Universitaire de France, Paris, France
}

\section{abstract}

Venus' convective cloud layers and associated gravity waves strongly impact the local and global budget of heat, momentum and chemical species. Here we use for the first time three-dimensional turbulence-resolving dynamical integrations of Venus' atmosphere from the surface to $100 \mathrm{~km}$ altitude, coupled with fully interactive radiative transfer computations. We show that this enables to correctly reproduce the vertical position (46-55 $\mathrm{km}$ altitude) and thickness (9 $\mathrm{km})$ of the main convective cloud layer measured by Venus Express and Akatsuki radio-occultations, as well as the intensity of convective plumes $(3 \mathrm{~m} / \mathrm{s})$ measured by VeGa balloons. Both the radiative forcing in the visible and the large-scale dynamical impact play a role in the variability of the cloud convective activity with local time and latitude. Our model reproduces the diurnal cycle in cloud convection observed by Akatsuki at the low-latitudes, and the lack thereof observed by Venus Express at the equator. The observed enhancement of cloud convection at high latitudes is simulated by our model, although underestimated compared to observations. We show that the influence of the vertical shear of horizontal super-rotating winds must be accounted for in our model to allow for gravity waves of the observed intensity ( $>1 \mathrm{~K}$ ) and horizontal wavelength (up to $20 \mathrm{~km}$ ) to be generated through the "obstacle effect" mechanism. The vertical extent of our model also allows us to predict for the first time a 7-km-thick convective layer at the cloud top (70 km altitude) caused by the solar absorption of the unknown UV absorber.

\section{Introduction}

The strong dynamical activity inside the Venusian cloud layer has been investigated for a long time. The convective activity was measured for the first time by the Pioneer Venus radio occulation experiment (Seiff et al. 1980) from 50 to $55 \mathrm{~km}$ above the surface and was then confirmed by other spacecraft like the Magellan probe (Hinson and Jenkins, 1995). The variability of the vertical extension of the convective layer has been studied 
in detail with the VeRa radio occultation device on board of Venus Express (Tellmann et al. 2009, 2012). A strong latitudinal variability of the vertical extent of the convective layer was observed (Tellmann et al., 2009), with the thickness of the convective layer reaching $10 \mathrm{~km}$ in polar regions, almost twice thicker than in the equatorial regions. No variability of the thickness of the convective layer with local time was measured in this dataset, though the radio occultations measured with the ongoing spacecraft Akatsuki measured a convective layer that appears to be thicker in the morning (Imamura et al., 2017). The amplitude of the vertical convective plumes, as well as the width of the convective cells, were measured in-situ by the VEGA balloons flying in the Venusian convective layer : vertical winds range between -3.5 and $2 \mathrm{~m} \mathrm{~s}^{-1}$ (Linkin et al., 1986) and convective cells extend horizontally from several hundred meters to tens of kilometers (Kerzhanovich et al. 1986).

Gravity waves emitted by this convective layer have been observed. Radio science profiling within and above the cloud layer evidenced small-scale waves with vertical wavelengths of about $7 \mathrm{~km}$ (Seiff et al., 1980 . Counselman et al. 1980). The Venus Express instruments also measured the wavelengths of the waves emitted above the cloud layer, which range between about 2 and $3.5 \mathrm{~km}$ along the vertical (Tellmann et al. 2012) and from $2 \mathrm{~km}$ to hundreds of kilometers in the horizontal (Peralta et al., 2008, Piccialli et al., 2014). From the Venus Monitoring Camera (VMC) images at high latitude, the waves seem to propagate towards the pole (Piccialli et al. 2014).

In addition to the convection layer inside the cloud, features observed at cloud-top by the Mariner 10 mission (Belton et al., 1976) and the Pioneer Venus spacecraft (Rossow et al., 1980) near subsolar point were morphologically close to convective cells with sizes between 200 and $1000 \mathrm{~km}$. The VMC observed the same cellular features at the top of the cloud, approximatively $70 \mathrm{~km}$ above the surface, at low latitude close to the subsolar point that might be attributed to convective motions Markiewicz et al. (2007); Titov et al. (2012). Convective cells from around 20 to a few hundreds of kilometers have been determined from these observations. With the nine years orbiting around Venus, the Venus Express mission yields a remarkable dataset of cloud top morphologies. Different regimes have been determined, from mottled dark clouds at low latitude to streaky clouds around $50^{\circ}$ and bright and almost featureless clouds at high latitude. Interestingly, while the low-latitude cloud-top images are reminiscent of convective activity, the Venus Express and Akatsuki radio occultation measurements at those altitudes in tropical regions do not show any clear neutral-stability layers (Tellmann et al. 2009, Ando et al., 2015, Imamura et al., 2017).

Aside from the observational efforts to characterize the cloud dynamics, the convective motions in the cloud layer and the resulting emission of gravity waves have been subject to modeling studies with two-dimensional models (Baker et al., 1998, 2000a b, McGouldrick and Toon, 2008, Imamura et al., 2014) and idealized threedimensional experiments (Yamamoto, 2014). Recently, Lefèvre et al. (2017) (hereafter L17) improved on those studies by proposing, for the first time, three-dimensional turbulence-resolving simulations with prescribed heating rates for shortwave, longwave, and large-scale dynamical forcings of the convective cloud layer. This enabled to evidence the horizontal organization of convective plumes as polygonal convective cells and the propagation of gravity waves both above and below the convective cloud layer. L17 also concluded that the thermal influence of the large-scale circulation (adiabatic warming/cooling associated with large-scale subsiding/ascending motions) 
is as important as the radiative forcing of the convective cloud layer. Yet, despite those improvements over existing modeling studies, both the thickness of the convective layer, the intensity of the convective plumes, and the amplitudes of the emitted gravity waves remained underestimated in the simulations of L17 compared to the available observations.

The goal of this paper is to further improve on the work by L17 by carrying out three-dimensional turbulenceresolving simulations with a more complete and realistic approach. The simulations in L17

1. did not include the wind shear present in the Venusian cloud layer where the large-scale super-rotating winds increase with altitude, while the pioneering two-dimensional simulations by Baker et al. (2000b) indicated that the wind shear had an impact on the development of the convection in the cloud layer and the associated gravity waves ;

2. used prescribed radiative heating rates (hereafter referred to as the "offline" mode), interpolated from Global Climate Modeling (GCM) calculations to the finer vertical grid used for convection-resolving simulations ;

3. only focused on the convective activity in the main cloud layer, with not enough vertical extent to investigate a possible convective activity at the top of the main cloud layer.

Here we propose unprecedented turbulence-resolving simulations coupled with fully interactive calculations of the radiative heating rates (hereafter referred to as the "online" mode) using the latest version of the radiative transfer scheme developed for the Institut Pierre-Simon Laplace (IPSL) Venus GCM (Lebonnois et al., 2016. Garate-Lopez and Lebonnois, 2018). Furthermore, our simulations are carried out with and without the inclusion of the vertical wind shear caused by Venus' super-rotating winds simulated in the IPSL Venus GCM. With this upgraded model, we revisit the study of L17 about the convective activity between 50 and $60 \mathrm{~km}$ and the induced gravity waves in the Venus cloud layer, and latitudinal and temporal variability thereof. We complement this by presenting the first modeling assessment of the potential convective motions at the top of the cloud at an altitude of about $70 \mathrm{~km}$.

Our paper is organized as follows. The model is described in Section 2 In Section 3 , the results on convective motions and gravity waves from a reference simulation for the main convective region are presented, as well as the variability of this dynamical activity with latitude and local time. The impact of wind shear on turbulent convection in the main cloud layer is discussed in Section 4. The convective activity at the top cloud layer is then investigated in Section 5 . Our conclusions are summarized in Section 6 .

\section{The model}

\subsection{Dynamical core}

Similarly to the modeling work of L17, this study is conducted using the fully-compressible non-hydrostatic dynamical core of the Weather Research and Forecast (WRF) terrestrial model (Skamarock and Klemp, 2008. Moeng et al., 2007). We use WRF in Large-Eddy Simulations (LES) mode : the grid spacing of the WRF 
model is refined to a couple hundreds meters so that the largest turbulent eddies (that is, convective plumes), responsible for most of the energy transport by buoyant convection, are resolved (Lilly, 1962; Sullivan and Patton, 2011). Past modeling studies (Baker et al., 2000a, Imamura et al., 2014, Lefèvre et al., 2017) showed that this LES modeling strategy allows to resolve the convective plumes in the unstable Venusian cloud layer, and the associated emission of gravity waves. Turbulent mixing by unresolved small-scale eddies is parameterized by a subgrid-scale "prognostic Turbulent Kinetic Energy" closure by Deardorff (1972), following the strategy adopted for terrestrial (Moeng et al., 2007) and Martian (Spiga et al., 2010) LES using WRF. Our Venus LES approach is not suitable to resolve small-scale turbulence in stable layers of the Venus atmosphere, although it is appropriate to study the propagation of gravity waves in those layers.

\subsection{Online coupling with complete physical packages for Venus}

The "offline" model used in L17 mainly consisted of WRF dynamical integrations forced by prescribed, fixedin-time, radiative and (large-scale) dynamical heating rates extracted from simulations with the IPSL Venus GCM (Lebonnois et al. 2010; Lebonnois et al., 2016). For the present study, we developed a complete "online" model by fully interfacing the WRF dynamical core with the whole set of Venus LMD physical packages used in the LMD Venus GCM. Our Venus LES are now designed equivalently to what was done for Mars by Spiga et al. (2010), promoting our Venus LES from category 2 LES to category 3 LES (according to the terminology described in section 2.4 of Spiga et al., 2016).

The calculations of the radiative heating rates (solar and IR) are made online from fluxes tables using the pressure and temperature of the domain. These calculations are perfomed with a time step ratio of 1300 between the dynamical and physical timesteps, given the long radiative timescales in the Venus atmosphere compared to the short timesteps (about one second, see next section) used for dynamical integrations.

The radiative transfer used for our turbulence-resolving simulations is similar to the one described in GarateLopez and Lebonnois (2018). The infrared (IR) transfer is based on Eymet et al. (2009) net-exchange rate (NER) formalism : the exchanges of energy between the layers are computed prior to the dynamical simulations, by separating temperature-independent coefficients from the temperature-dependent Planck functions of the different layers. These temperature-independent coefficients are then used in the online model to compute the infrared cooling rates of each layer. The solar heating rates are based on computations by Haus et al. (2015) : we use look-up tables of vertical profiles of the solar heating rate as a function of solar zenith angle, that are then interpolated on the fine-resolution vertical grid of our Venus LES model.

The cloud model is based on Haus et al. (2014) and Haus et al. (2015) and uses recent retrievals from Venus Express observations. This cloud model takes into account the latitudinal variation of the cloud structure, especially the cloud top variation Haus et al. (2014). The latitudinal variation of the cloud is accounted for by setting 5 distinct latitude intervals : $0^{\circ}$ to $50^{\circ}, 50^{\circ}$ to $60^{\circ}, 60^{\circ}$ to $70^{\circ}, 70^{\circ}$ to $80^{\circ}$ and $80^{\circ}$ to $90^{\circ}$. Different NER-coefficients matrices are computed for these five latitudinal bands over the 300 vertical levels of the model, ranging from the surface to roughly $100 \mathrm{~km}$ altitude. 
As evidenced in L17, the heating/cooling caused by the general circulation (adiabatic cooling/heating by ascending/subsiding large-scale motions) has a significant impact on the dynamics of the convective layer. Therefore, in addition to the solar and IR radiative heating rates now computed online by our Venus LES, we add as in L17 a prescribed term accounting for the adiabatic cooling / warming due to the large-scale dynamics of the atmosphere. This heating rate is extracted from the IPSL Venus GCM reference simulation in Garate-Lopez and Lebonnois (2018) at the local time targeted for the Venus LES modeling. After extracting the same local time for all longitudes, a zonal mean is performed at the targeted latitude to remove wave-induced longitudinal perturbations. The six cases of the large-scale dynamical are shown in Figure 1 with associated large-scale vertical wind .
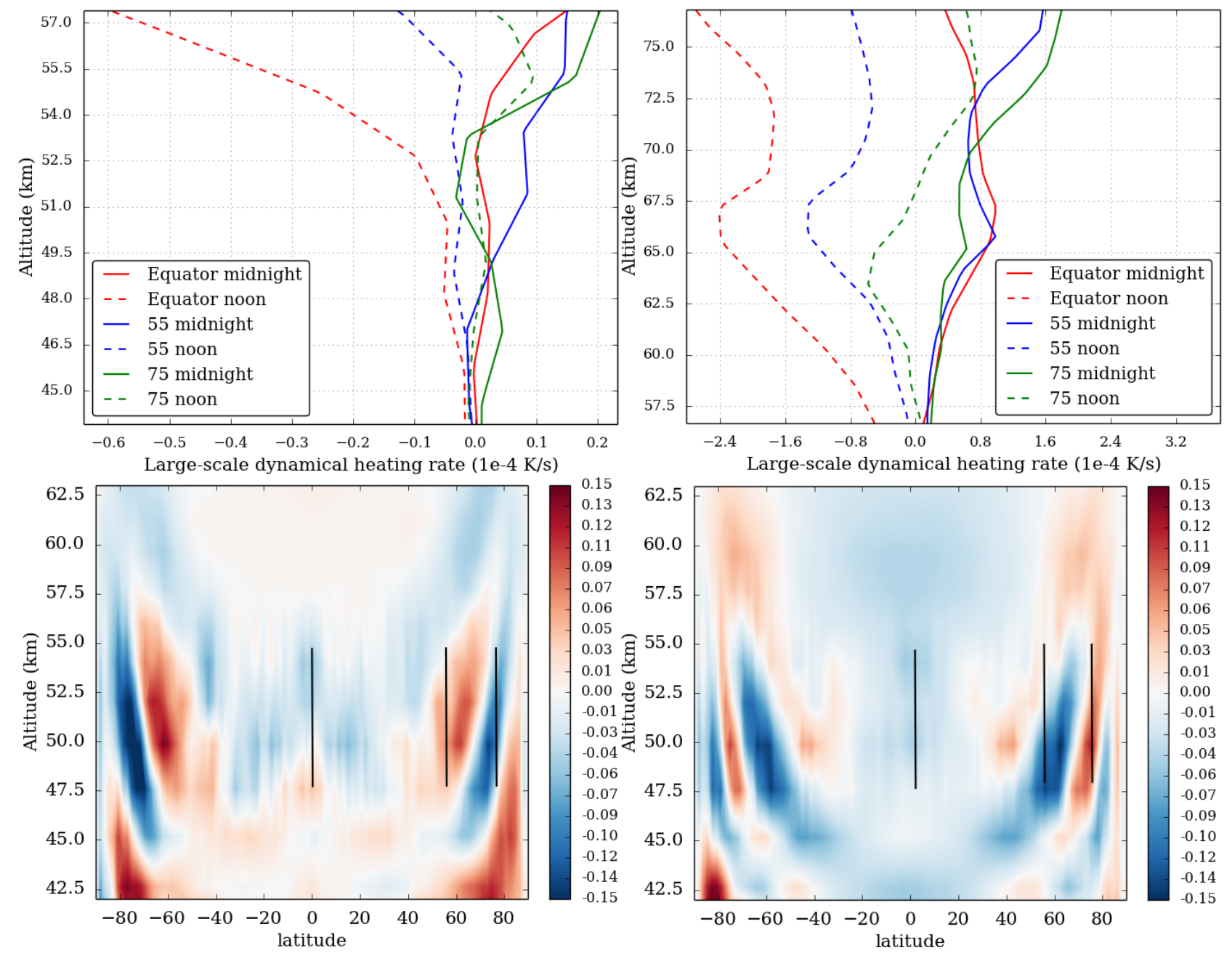

Figure 1 - Top : Vertical profile of the large-scale dynamical heating rate $\left(10^{-4} \mathrm{~K} \mathrm{~s}^{-1}\right)$ between 45 and $57 \mathrm{~km}$ and from 57 to $75 \mathrm{~km}$. Bottom : Vertical wind of the LMD Venus GCM in (Pa s${ }^{-1}$ ) at night (left) and noon (right) between 42 and $63 \mathrm{~km}$. Positive value of vertical means downward wind and positive value means upward wind. The black lines represent the convective activity vertical extension.

The dynamical equations implemented in WRF make use of potential temperature (field and perturbations) instead of temperature, while the physical packages from the IPSL Venus GCM make use of temperature. The WRF dynamical core is built with a constant heat capacity, which is set to $900 \mathrm{~J} \mathrm{~kg}^{-} 1 \mathrm{~K}^{-1}$ for this study, while the physical package uses a varying heat capacity. The conversion from potential temperature to temperature, and vice versa, is computed as in (Lebonnois et al. 2010) using a heat capacity $C_{p}$ varying with temperature. 
The initial profile of potential temperature used in the Venus LES is also computed with a varying heat capacity, to be consistent with the GCM integrations from which it is extracted.

\section{$2.3 \quad$ Simulation settings}

The implementation of the LMD Venus physics, and the use of the NER formalism for IR radiative transfer, requires the full vertical domain of the IPSL Venus GCM to operate, i.e. from the ground to $\sim 100 \mathrm{~km}$. The calculations are therefore carried out on this extended vertical range. The dynamical analysis in this study focuses on the Venusian cloud layer and the gravity waves emitted above this convective layer, thus all the figures presented here only display a vertical extent from 40 to $75 \mathrm{~km}$. The study of the convective motions in the Planetary Boundary Layer is left for future work, as it would require different horizontal and vertical grids than the one presently adopted for the study of the cloud convection (Yamamoto, 2011).

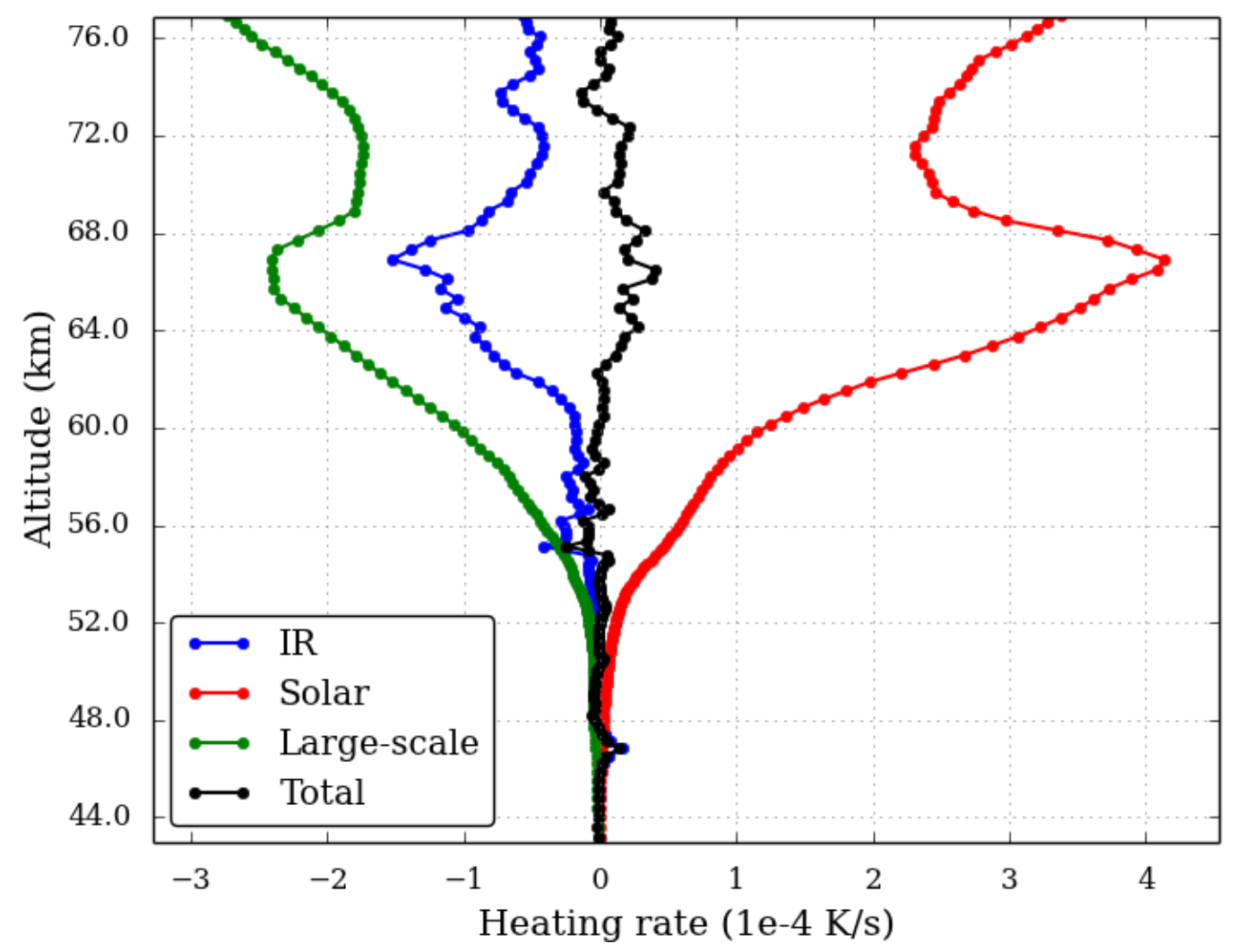

FiguRE 2 - The forcing in the Venus cloud region : solar, infrared (IR), large-scale dynamical and the total heating rates $(\mathrm{K} / \mathrm{s})$ in the equatorial condition at noon.

For the sake of illustration, Figure 2 shows the three heating rates : the two solar and IR radiative rates computed by the online model and the large-scale dynamical heating rate prescribed from GCM precomputed simulations and the total heating rate, at the equator at noon between 40 and $76 \mathrm{~km}$. The solar heating rate is strictly positive with a maximum around $66 \mathrm{~km}$ due to the unknown UV absorber (Haus et al. 2015). The infrared heating rate is mainly negative except around $46 \mathrm{~km}$, the base of the cloud, where it becomes strongly positive. The dynamical heating rate is strictly negative due to the ascending branch of the Hadley cell (Figure 1).

The chosen horizontal resolution for our convective cloud modeling is $400 \mathrm{~m}$ with a grid mesh comprising 
151 points : the extent of the horizontal domain is $60 \mathrm{x} 60 \mathrm{~km}$. The vertical domain is composed of 300 points approximately equally distributed, except for a refined area where the convective activity takes place. The resolution inside the convective layer is in average of $150 \mathrm{~m}$ against $300 \mathrm{~m}$ for the remainder of the vertical column. This vertical grid is different than the one adopted in the IPSL Venus GCM, thus the NER matrices were recomputed to suit the needs of our Venus LES modeling.

The choice of spatial (horizontal and vertical) resolution requires a dynamical integration timestep of $1.5 \mathrm{~s}$, as a trade-off between numerical stability and computational efficiency, and small enough to provide high temporal resolution over the lifetime of a convective cell. The horizontal boundary conditions are periodical. At the top of the domain, a Rayleigh sponge layer of $8 \mathrm{~km}$ height and a damping coefficient of $0.06 \mathrm{~s}^{-1}$ is set to avoid spurious reflection of upward-propagating gravity waves on the (artificial) model top around $100 \mathrm{~km}$ altitude.

The initial fields (temperature, pressure, winds) for the LES integrations are extracted at a given latitude/local time from the IPSL Venus GCM simulation (Garate-Lopez and Lebonnois, 2018) that uses the exact same solar and IR radiative transfer as the LES integrations. In this study we performed simulations using distinct initial fields and settings in the physics, corresponding to several local times and latitudes. Simulations are performed using 3 different latitudes, at the equator, $55^{\circ} \mathrm{N}$ and $75^{\circ} \mathrm{N}$. We choose 2 local times, midnight and noon, that are fixed during the entire corresponding Venus LES run. We remind the reader with the important point raised in L17 that our simulations are run long enough so that the combination of $\underline{\text { radiative and (large-scale) dynamical heating rates act to destabilize the initial atmospheric profile and to cause }}$ convective instability, hence the mixed profile obtained in the cloud layer stems from the plumes resolved by LES integrations. We found that running about 10 Earth days is necessary before the convective motions in our Venus LES reach a steady state at fixed local time.

\section{Main layer : Convection and gravity waves}

In this section, we focus on the main convective layer between 40 and $65 \mathrm{~km}$. We first discuss the convective activity and gravity waves of a Venus LES run in the equatorial conditions at noon, before analyzing the variability of this convection layer with local time and latitude. Hereafter the overline $\bar{X}$ denotes the domainaveraged and the apostrophe $X^{\prime}$ denotes the perturbation, i.e. the fields minus the average $X^{\prime}=X-\bar{X}$.

\subsection{Simulated Convection}

Figure 3 shows the vertical profiles of the domain-averaged potential temperature (left) and static stability (right) at the equator at noon between 42 and $65 \mathrm{~km}$. The zero value of the static stability (or, equivalently, the constant value of the potential temperature) indicates that the convection takes place between approximately 46.5 and $55.5 \mathrm{~km}$. In the radio occultation measurements of VeRa the convective layer at the equator was located between approximately 49 and $59 \mathrm{~km}$ (Tellmann et al., 2009). The first radio occultations on-board Akatsuki (Imamura et al., 2017) measured a vertical extension of the convective layer from 50 to $58 \mathrm{~km}$. Thus, the bottom of the convective layer resolved in our Venus LES is slightly lower than the observations, but the thickness is 
consistent.

The predicted thickness is twice thicker in our present simulations than in the previous results described in L17, which were obtained through a LES model using prescribed radiative heating rates derived from GCM calculations. We conclude that radiative transfer computations at fine vertical resolution is necessary to correctly reproduce the vertical extent of the convective layer in a turbulence-resolving model. Both above and below the convection layer stands a region of high stability, with a maximum of static stability around $63 \mathrm{~km}$. Both the amplitude, and altitude of occurrence, of these stable regions are consistent with the VeRa radio occultations near the equator.

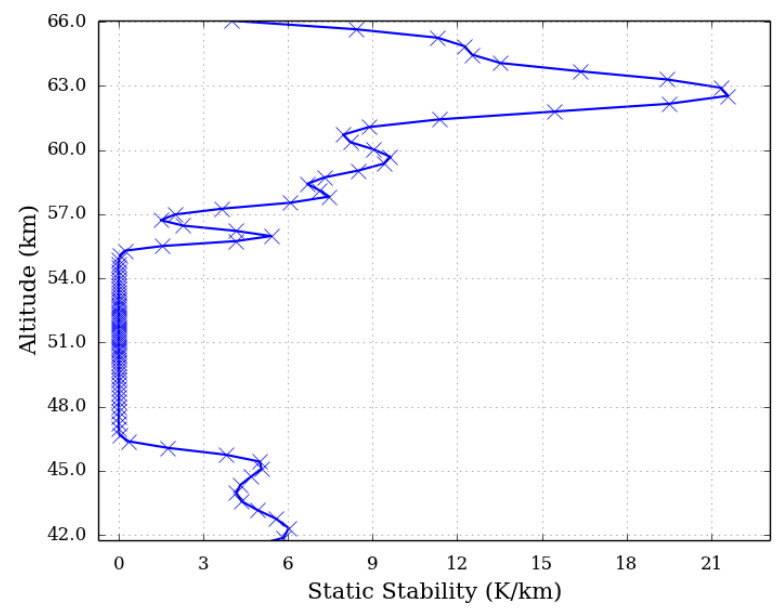

Figure 3 - The Venus cloud mixing layer : domain averaged potential temperature (K) (left) and static stability $(\mathrm{K} / \mathrm{km})$ (right) between 42 and $65 \mathrm{~km}$ in the equatorial condition at noon.

The convective motions are depicted in Figure 4 by two snapshots : a vertical cross section in the middle of the domain (left) and a horizontal cross section in the middle of the convective layer at $51 \mathrm{~km}$ (right). The values of the vertical wind vary between about $2 \mathrm{~m} \mathrm{~s}^{-1}$ for updrafts, and almost $-3 \mathrm{~m} \mathrm{~s}^{-1}$ for downdrafts. Those vertical wind velocities are consistent with measurements obtained by the VeGa balloons (between -3.5 and $2 \mathrm{~m} \mathrm{~s}^{-1}$, Linkin et al., 1986). This is, again, a key improvement compared to our previous work in L17. As the convective layer is thicker with the complete radiative transfer, the vertical wind inside the convective layer is stronger - about twice the amplitude obtained with the prescribed heating rates.

The convective motions are organized on the horizontal plane as polygonal closed-cells with a "diameter" of about $20 \mathrm{~km}$ width. This is larger than L17, consistently so with the above-mentioned conclusions since the extent of polygonal cells scales approximately with the thickness of the convective layer. These values are consistent with the broad convective cells encountered by the VeGa balloons (Kerzhanovich et al., 1986). The aspect ratio of the convective cells is quite low compared to one observed for the closed convective cells on the Earth (between 3 and 28, Atkinson and Wu Zhang, 1996).

What is the heat transport caused by the resolved convective motions in our Venus LES? Figure 5 shows the vertical convective heat flux defined as $C_{p} \rho \overline{w^{\prime} \theta^{\prime}}$ with $C_{p}$ the specific heat, $\rho$ the density calculated with the ideal gas law, $w^{\prime}$ the vertical wind perturbation and $\theta^{\prime}$ the potential temperature perturbation. As is described in L17, the convective layer consists of the mixing layer, between 46.0 and $55.5 \mathrm{~km}$, which is bounded by an 

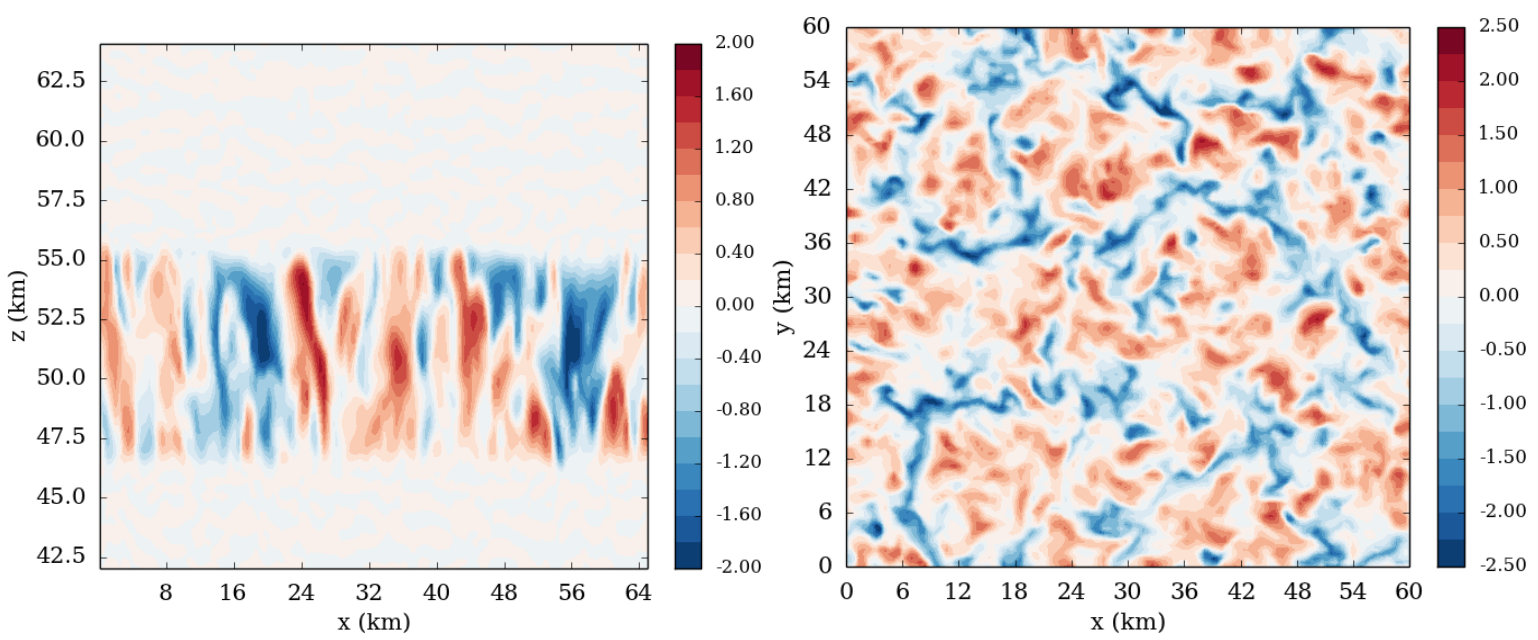

FIGURE 4 - Snapshots of the cloud convective vertical motions : vertical cross-section at $\mathrm{y}=20 \mathrm{~km}$ between 42 and $65 \mathrm{~km}$ of altitude (left) and horizontal cross-section at $51 \mathrm{~km}$ of the vertical wind ( $\mathrm{m} \mathrm{s}^{-1}$ ) (right) at the Equator at noon.

updraft-induced entrainment layer $(55.5$ and $56.0 \mathrm{~km})$ and a downdraft-induced entrainment layer (46.0 to $45.7 \mathrm{~km}$ ). The convective heat flux reaches $18.0 \mathrm{~W} \mathrm{~m}^{-2}$ at maximum, almost twice the value obtained by the model of Imamura et al. (2014).

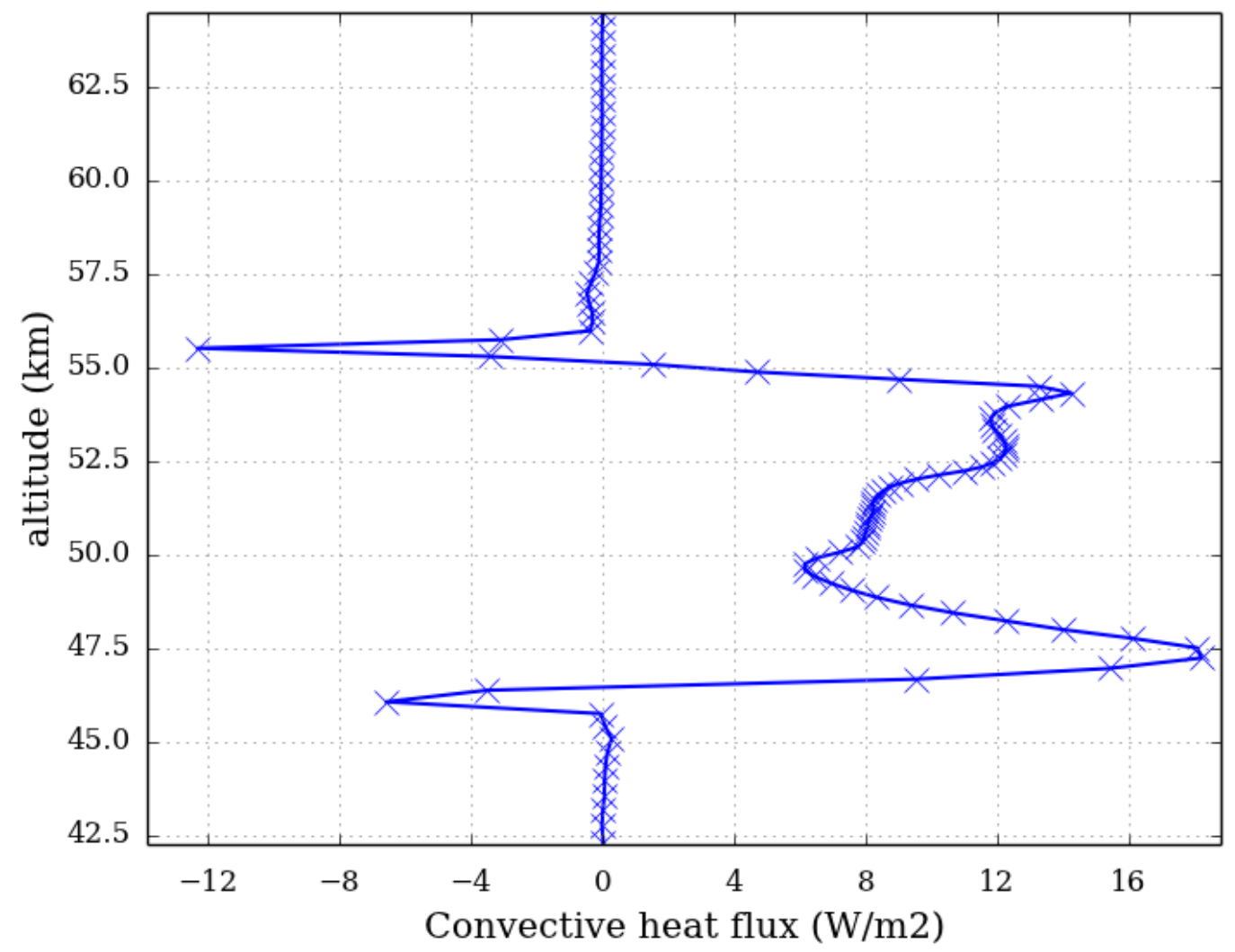

FiguRE 5 - Domain averaged vertical profile of the turbulent heat flux $\left(\mathrm{W} \mathrm{m}^{-2}\right)$ of the Venus cloud convective layer for Equatorial condition at noon. 


\subsection{Gravity waves}

Fig 6 features two snapshots of the induced gravity waves : a vertical cross section in the middle of the domain of the temperature perturbation (left) and a horizontal cross section at $57 \mathrm{~km}$ of the vertical wind perturbation (right). The temperature perturbations range between approximately -0.7 and $0.5 \mathrm{~K}$. These values are about five times stronger than the previous version of the model described in L17, although still weaker than the VeRa observations by about a factor of two (Tellmann et al., 2012). The wave amplitude simulated by our Venus LES is consistent with the values obtained in the modeling work of Imamura et al. (2014) and Yamamoto (2014), with a similar vertical extent of the convective layer and no background wind. As in L17, the wavefronts in the horizontal plane are circular due to the absence of wind shear. The impact of the background wind on the gravity waves will be discussed in Section 4
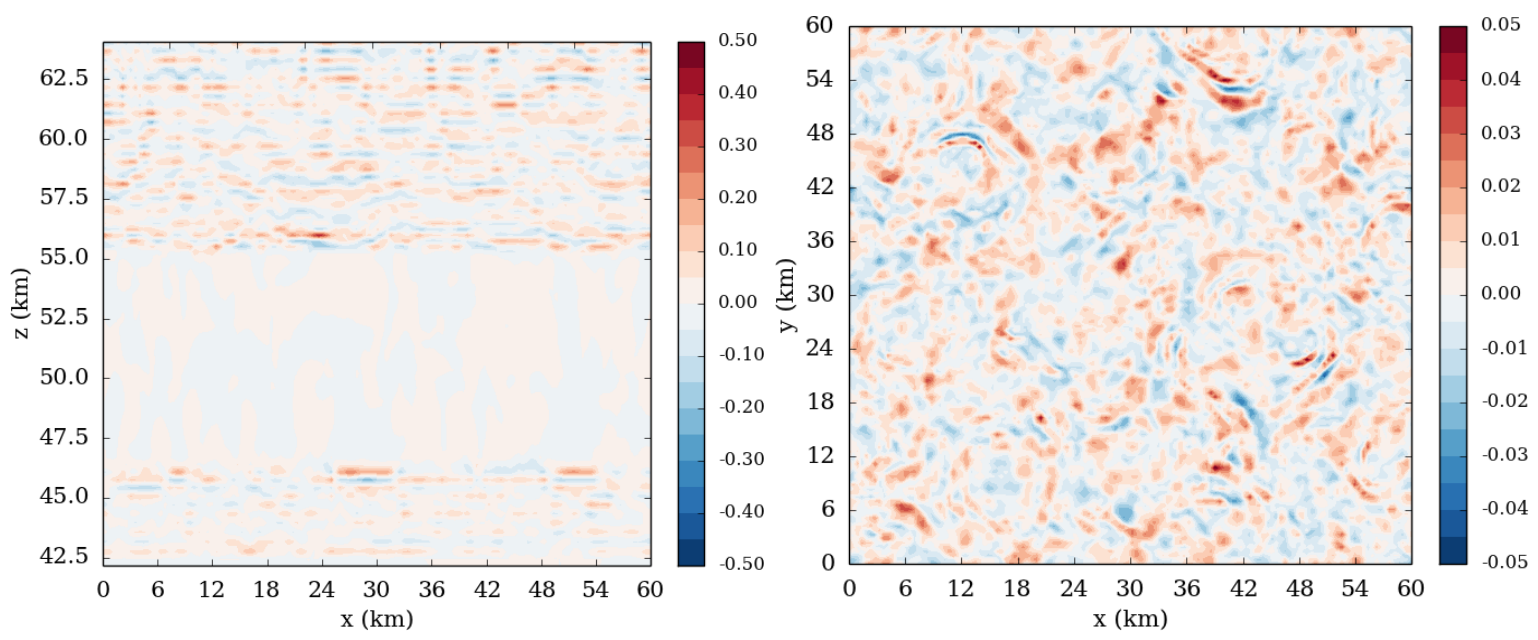

FIgURE 6 - Snapshots of the induced gravity waves : vertical cross-section at y $=20 \mathrm{~km}$ of the temperature perturbation $(\mathrm{K})$ between 42 and $65 \mathrm{~km}$ (left) and horizontal cross-section at $57 \mathrm{~km}$ of the vertical wind perturbation $\left(\mathrm{m} \mathrm{s}^{-1}\right)$ (right), at the Equator at noon.

Using the continuous wavelet transform 1 , with the Morlet wavelet defined in Torrence and Compo (1998), we calculate the horizontal and vertical wavelengths of the gravity waves. Wavelet analysis indicates that the horizontal wavelengths range from 1 to $6 \mathrm{~km}$ at an altitude of $57 \mathrm{~km}$. These values are very similar to the ones obtained with our previous model. The simulated horizontal wavelengths are on lower side of the spectrum observed by VMC (2 to $20 \mathrm{~km}$, Piccialli et al., 2014). The vertical wavelength ranges from 1 to $2 \mathrm{~km}$, similar to the previous model and consistent with VeRa measurements (Tellmann et al., 2012).

With the formalism described in L17, and borrowed from Frits and Alexander (2003), the dispersion relation and group speed are calculated. A horizontal wavelength between 1 and $6 \mathrm{~km}$ is assumed in the two horizontal directions, with a vertical wavelength of $1.5 \mathrm{~km}$, and a squared Brunt-Väisälä frequency $N^{2}$ value of $10^{-4} \mathrm{~s}^{-2}$ consistent with the Pioneer Venus observations (Gierasch et al., 1997). At an altitude of $57 \mathrm{~km}$, this leads to an intrinsic frequency $\widehat{\omega}=N^{2}\left(k^{2}+l^{2}\right) /\left(k^{2}+l^{2}+m^{2}\right)$, where $k, l$ and $m$ the wavenumber along respectively the $\mathrm{x}$-axis, the $\mathrm{y}$-axis and the $\mathrm{z}$-axis, between $3.3 \times 10^{-3}$ and $9.0 \times 10^{-3} \mathrm{~s}^{-1}$. The angular frequencies are close to the Brunt-Väisälä frequency, hence the gravity waves belong to high-frequency regime. Assuming zero background

1. Python software by Evgeniya Predybaylo, available in this URL http ://paos.colorado.edu/research/wavelets 
wind, the associated horizontal group velocity ranges from 0.18 to $2.00 \mathrm{~m} \mathrm{~s}^{-1}$ and the vertical component from 0.39 to $0.70 \mathrm{~m} \mathrm{~s}^{-1}$.

\subsection{Variability with local time and latitude}

Figure 7 shows the comparison of the mean static stability at the Equator for noon and midnight between 42 and $63 \mathrm{~km}$. The difference of thickness of the convective layer between noon and midnight is hardly noticeable, echoing the variability observed by the VeRa experiment. The modeling work of Imamura et al. (2014) found a strong solar inverse dependence on insolation, observed also in the first results of Akatsuki radio occultations. The heating at the base of the convection is driven by the IR heating in both cases. Above, at noon large-scale dynamical heating rate is negligeable in front of the radiative rates whereas at night the solar heating is mainly compensated by the large-scale dynamical heating rate, resulting to a rate very close to the nighttime large-scale dynamical heating rate. At the Equator, because of the daytime large-scale dynamical heating rate, there is no variability of the convection thickness.

At midnight, a very thin 1-kilometer-deep layer of low static stability is present at approximately $62 \mathrm{~km}$. The atmosphere is destabilized by the combination of IR and positive large-scale dynamical heating. The largescale dynamical heating rate is positive and increasing constantly with altitude at night due to the large-scale descent on the nightside. The IR heating rate in that area (between 58 and $60 \mathrm{~km}$ ) is negative and constant with altitude and decreasing above. The total rate is therefore positive around $60 \mathrm{~km}$ and then negative around $62 \mathrm{~km}$ leading to a small destabilization leading to a week convection. At noon the strong solar heating is stabilizing this region. This unstable zone corresponds to the altitude of the decrease of the number of cloud particles in the distribution of mode 2'(Haus et al. 2015). The decrease of the number of cloud particles induces a modification of the IR heating. In our model, this destabilization is too strong compared to observations, maybe because the large-scale dynamical heating rate is not as realistic as is the radiative rate. This thin low-stability layer is also found at other latitudes and local times, approximately at the same altitude (Figures 9).

One of the key consequences of this low static stability layer lies in the perturbations of the vertical propagation of the gravity waves, similar in many aspects to the VeRa measurements (Tellmann et al., 2012). Figure 8 shows a comparison of the temperature perturbations (K) at the Equator for noon (left) and midnight (right) between 42 and $63 \mathrm{~km}$. The amplitude of the waves is slightly stronger at midnight, due to the stronger convection, but what is mostly noticeable is the strong attenuation around $61 \mathrm{~km}$ induced by the low static stability layer.

Radio-occultation profiling of the convective layer (Tellmann et al., 2009, Ando et al., 2015, Imamura et al. 2017) shows that the thickness of the convective layer increases with latitude. Both the bottom and top boundaries of the convective layer also appear to change with latitude. No variability with local time was observed with the Venus Express measurements whereas some amount of variability was detected by Akatsuki. Figure 9 shows the comparison of the mean static stability for the three latitudes at noon (left) and midnight (right). To be able to compare properly the latitudinal cases, the 2 figures are presented with pressure as y-axis. At noon 


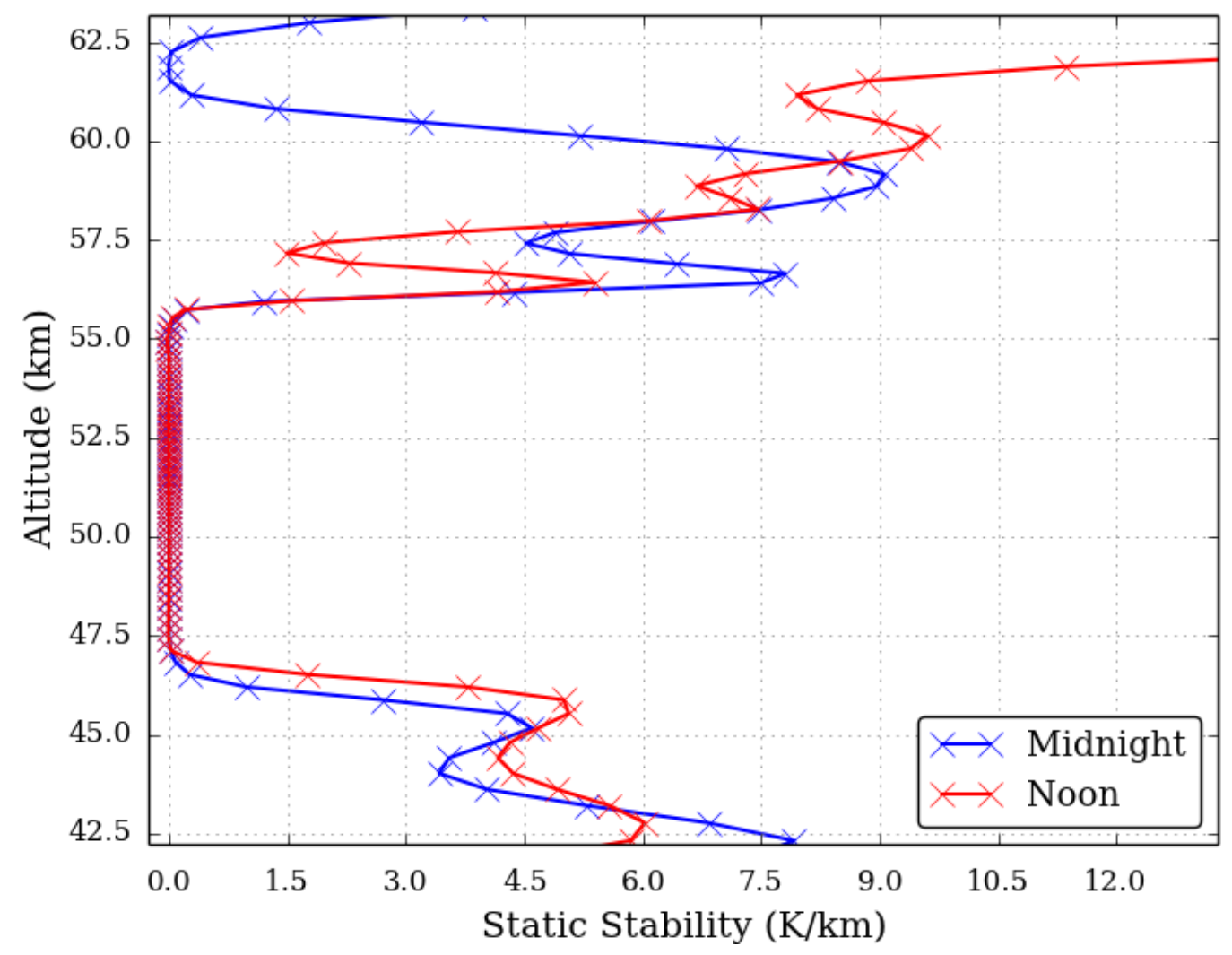

Figure 7 - Comparison of the vertical profile of the domain averaged static stability $(\mathrm{K} / \mathrm{km})$ for equatorial condition at noon and midnight between 42 and $63 \mathrm{~km}$.
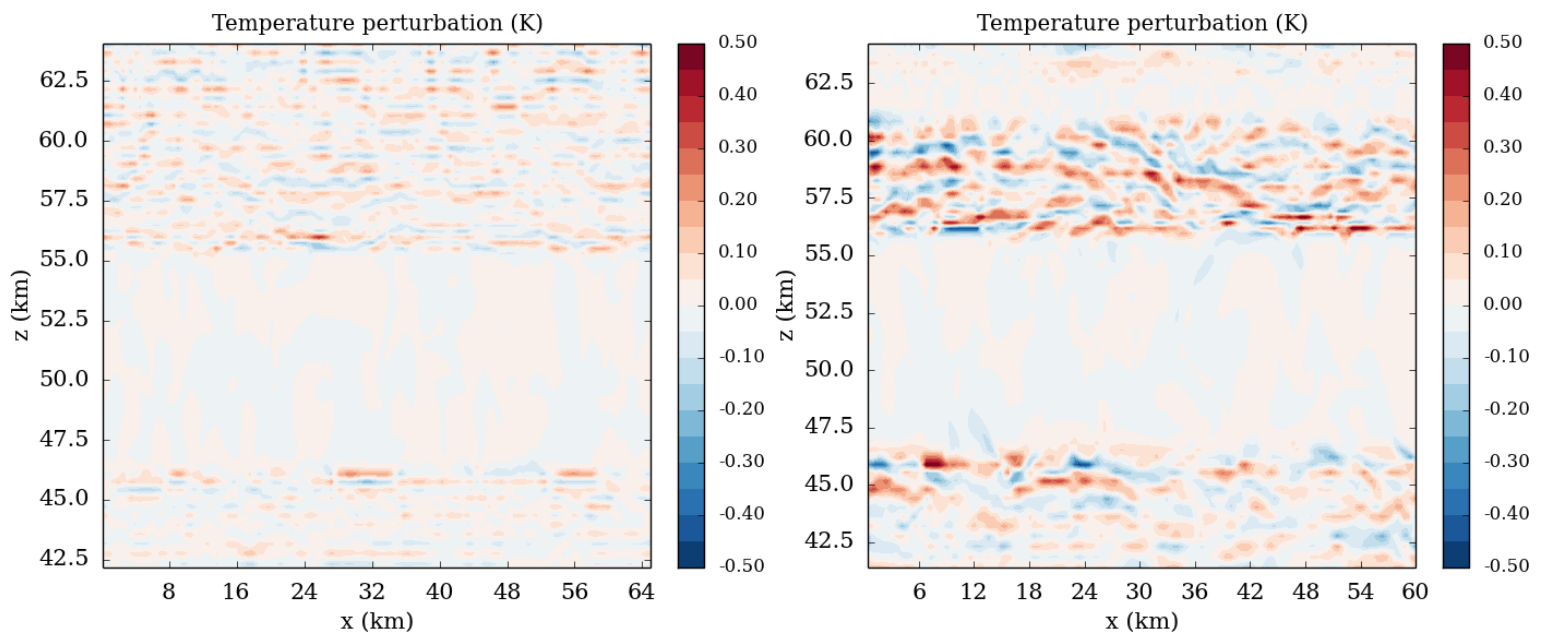

FIGURE 8 - Comparison of the induced gravity waves : temperature perturbation (K) at the Equator for noon (left) and midnight (right) between 42 and $63 \mathrm{~km}$.

the convective thickness for the Equator and $55^{\circ}$ latitude are very close, whereas at $75^{\circ}$ the convective layer extends towards a higher altitude - almost $2 \mathrm{~km}$ higher. At midnight the convective thickness for the Equator and $75^{\circ}$ are very similar while at $55^{\circ}$ latitude the convective layer goes at higher altitude, about $3 \mathrm{~km}$ higher.

The altitude of the bottom boundary of the convective layer does not change with latitude nor with local time. The bottom of the convective layer is controlled by the maximum of IR heating, that does not change in altitude because the cloud bottom is fixed in the cloud model Haus et al. (2015), although variations of the bottom cloud boundary are observed (Cimino, 1982; Barstow et al. 2012$)$. Meanwhile the top boundary of the 
convective layer does vary with latitude and local time. The top of the convective layer is controlled by the energy exchange between the cloud and space through a maximum of IR cooling. At $55^{\circ}$ latitude at midnight, the large-scale dynamical heating rate is positive due to the descending branch of the Hadley cell (Figure 1 ) and superior in amplitude to the IR radiative rate. The total rate is positive almost along the entire convective layer, adding more heat to be mixed. Therefore the convection needs to go at higher altitude. At noon, the large-scale dynamical heating rate is negative and compensates the solar heating inside the convective layer. At $75^{\circ}$ a similar mechanism is at play. At noon, the large-scale dynamical heating rate is positive along the convective layer, adding with the solar heating more heat to be mixed, while at midnight the large-scale dynamical heating rate is negligible compared to the IR cooling. Both the top and bottom boundaries of the convective layer are controlled by the IR radiative transfer, but the large-scale dynamical heating rate can play a key role to modify the top of the layer.
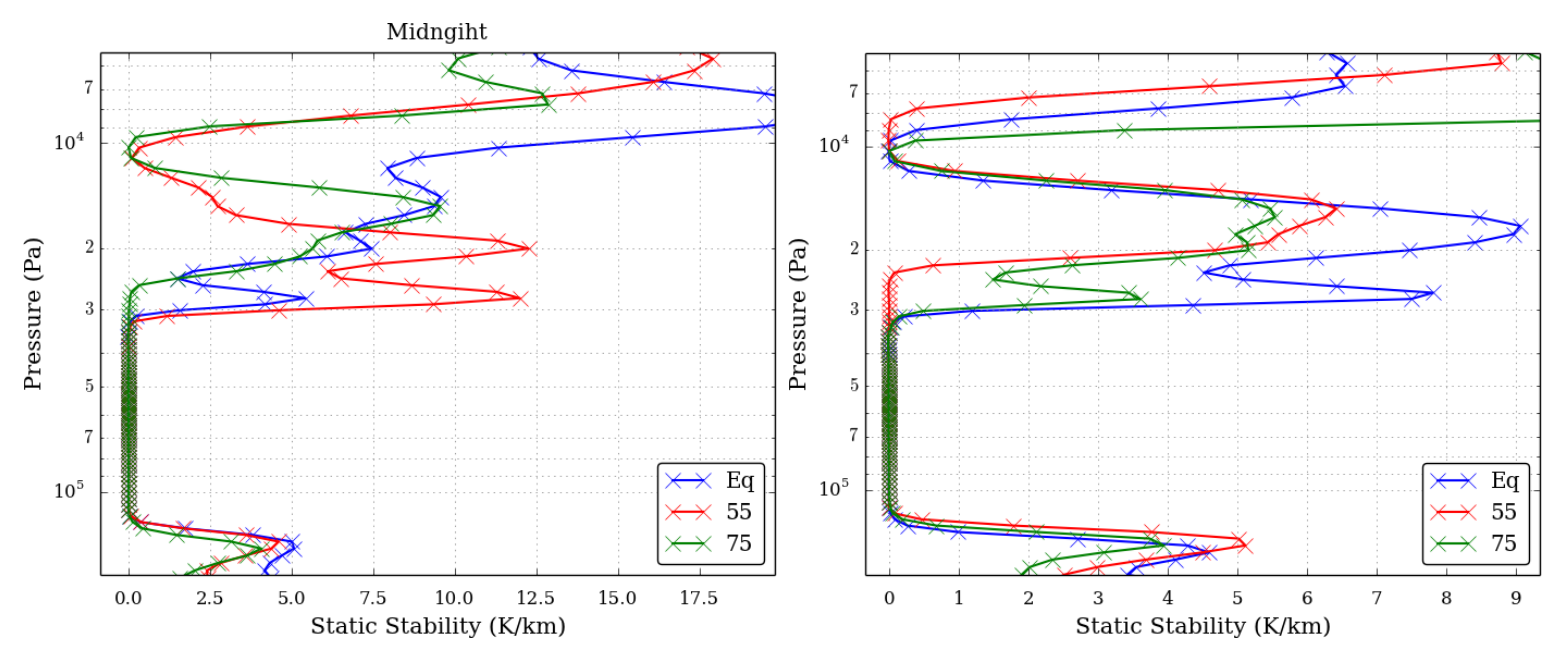

FiguRE 9 - Comparison of the vertical profile of the domain averaged static stability $(\mathrm{K} / \mathrm{km})$ for the Equator, $55^{\circ}$ and $75^{\circ}$ of latitude at noon (left) and midnight (right).

Another factor that is variable with latitude is the time for the convection to develop and reach a steady state. With the implementation of the radiative scheme, this time increased : in the "offline" simulations of L17 it was 1 to 2 Earth days, while in the present "online" simulations it is from 4 to more than 10 Earth days. The implementation of the latitudinal variability of the cloud induced a modification of the large-scale dynamical heating rates in the convective region. The development of the convection to stabilize this region is affected by these different large-scale dynamical heating rates. A second possible explanation for the longer time needed to reach steady-state is that including the full radiative transfer scheme couples the temperature structure and the IR cooling rates. When developing, the convective layer appears first separated in two convective layers that end up connecting each other and forming one single convective layer, as shown in Figure 4 . This two-convectivelayer transient phase remains for a longer time at $55^{\circ}$. Such a separation in the convective layer appeared in some of the observed Magellan static stability profiles (Hinson and Jenkins, 1995). Our simulations suggest that this may be related to the influence of the large-scale dynamical heating rate.

The "online" coupling of the turbulence-resolving WRF dynamical core with the LMD physics radiative scheme enables our Venus LES runs to reproduce a convective layer that is more in agreement with the ob- 
servations, especially at high latitudes, than the "offline" Venus LES presented in L17 with prescribed heating rates. A vertically-refined radiative transfer was crucial to model properly the Venus cloud convective layer. The variations with latitude and local time of the convective layer are also more consistent with observations in our "online" Venus LES than in the "offline" version presented in L17. Despite the better agreement with observations for the convective layer, the induced gravity waves amplitude and wavelengths remain below measured values. We now turn to Venus LES including wind shear to address this remaining discrepancy.

\section{Impact of the wind shear}

In this section we will study the impact of the wind shear on the convection and induced gravity waves. We carried out Venus LES runs similar to the ones described in the previous section, except that an ambient (background) wind profile is prescribed throughout the simulations. Figure 10 shows this background zonal and meridional wind at noon (left) and midnight (right) vertical profile. Those profiles of background winds are the same in every grid points of the LES domain. They are extracted from the IPSL Venus GCM simulation of Garate-Lopez and Lebonnois 2018) and interpolated on the LES vertical grid. Please note that positive meridional velocity means poleward velocity.
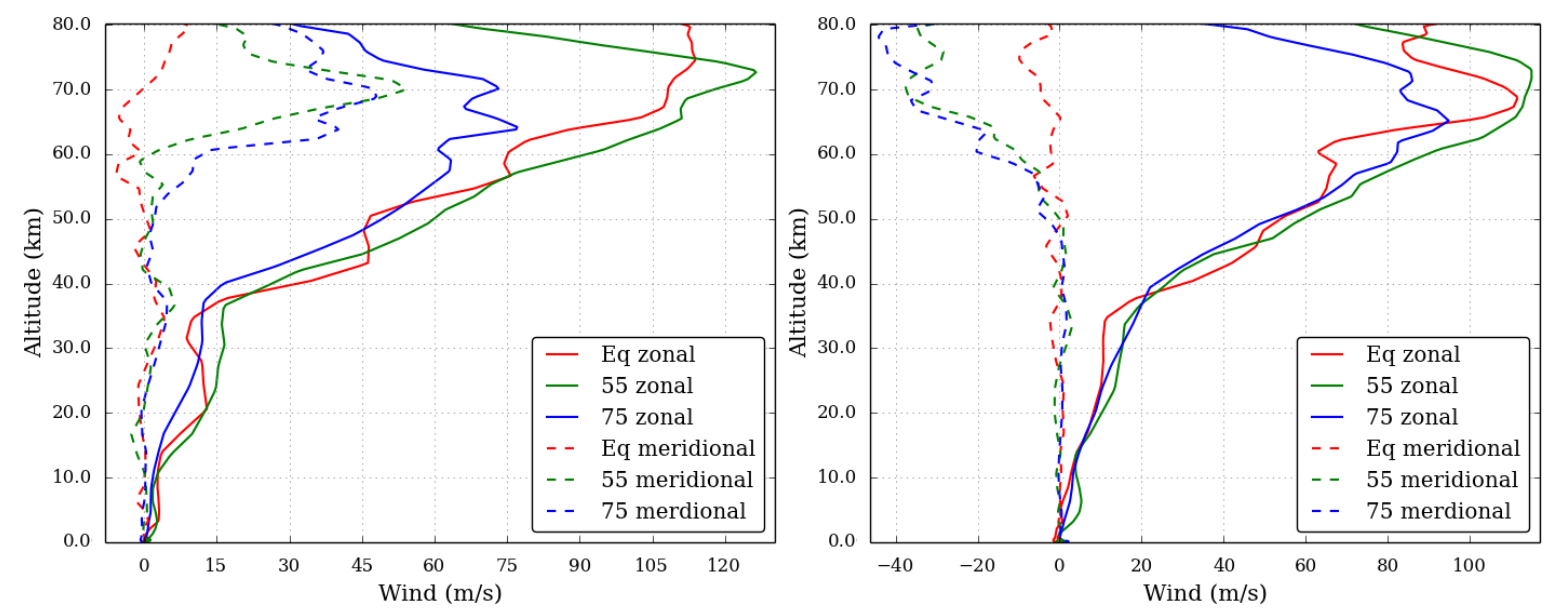

Figure 10 - Vertical profile of the input zonal and meridional winds at noon (left) and midnight (right) for the Equator, $55^{\circ}$ and $75^{\circ}$ of latitude.

The comparison of the mean static stability profile with or without wind shear at the Equator at midnight (left) and noon (right) is shown in Figure 11. The impact of the presence of the wind shear on the vertical extent of the convective layer is hardly noticeable. This conclusion stands for higher-latitude Venus LES runs. This is expected since the convection of the Venusian cloud layer is mostly buoyancy-driven and not shear-driven.

The impact of wind shear is expected to be significant on the gravity waves emitted by convective motions in the cloud. Wind shear modifies the frequency of the wave $\omega=\widehat{\omega}+\vec{k} \cdot \vec{U}$ (with $\widehat{\omega}$ the intrinsic frequency, $\vec{k}$ the wave vector and $\vec{U}$ the horizontal wind vector), thus the horizontal phase and group wave speed. It also has an impact on the gravity wave source. In addition to the generation of waves by the updrafts and downdrafts, similar to a mechanical oscillator (Clark et al., 1986, Ansong and Sutherland, 2010), the interaction of the flow with the convective overshoot also causes a secondary wave generation to occur, called the obstacle 

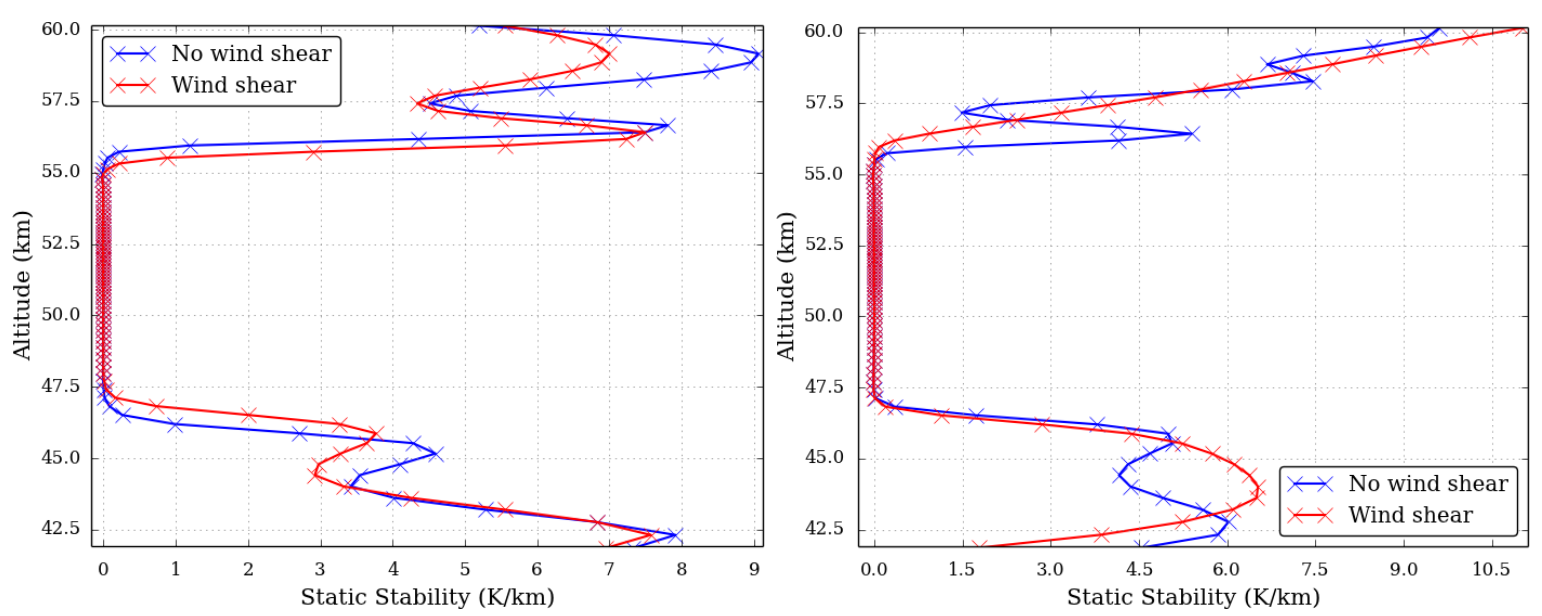

FIgURE 11 - Comparison of the vertical profile of the domain averaged static stability $(\mathrm{K} / \mathrm{km})$ at cloud top between the presence of a wind shear and no wind shear for equatorial condition at midnight (left) and noon (right).

effect (Mason and Sykes, 1982, Clark et al., 1986). The overshoot both below and above the convective layer are acting like low hills in orographically-triggered gravity waves near the surface. The generation of gravity waves by the mechanical oscillator effect is characterized by high frequencies and short wavelengths with prefered horizontal direction propagation, while the obstacle effect produces longer wavelength features propagating against the background wind (Fovell et al., 1992). The first modeling studies with three-dimensional simulations of convection and convectively generated gravity waves from the surface to $100 \mathrm{~km}$ has been performed by Horinouchi et al. (2002); Horinouchi (2004). On Venus, numerical modeling by Baker et al. (2000b) evidenced that the impact of the wind shear was strong on the generation and propagation of gravity waves. Yamamoto (2014) found a similar trend on the gravity waves by increasing the background wind.
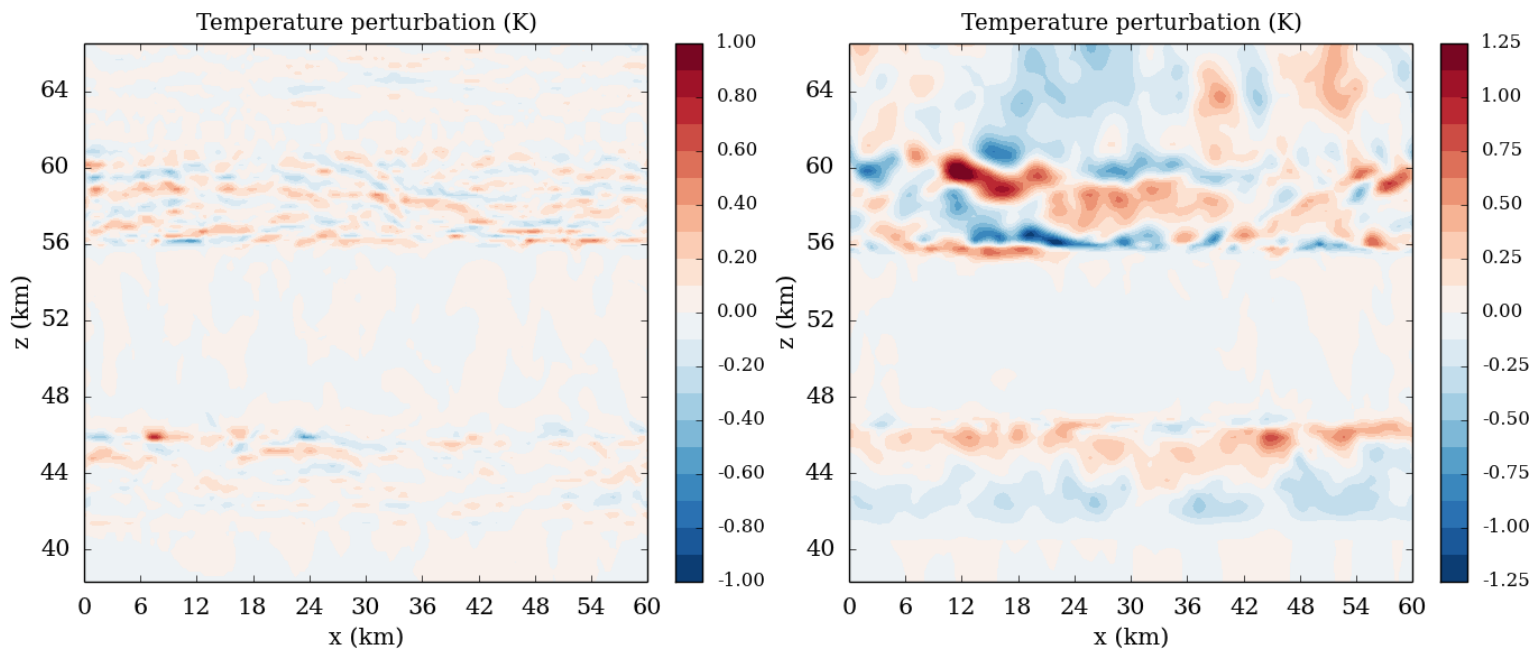

FIgURE 12 - Impact of the wind shear : Comparison of two snapshots of the temperature perturbation (K) at the Equator at midnight without (left) and with (right) wind shear.

Figures 12 and 13 show the comparison of two snapshots of the temperature $(\mathrm{K})$ and vertical wind $\left(\mathrm{m} \mathrm{s}^{-1}\right)$ perturbations at the Equator at midnight without (left) and with (right) wind shear. In the case of the presence of the wind shear, the amplitude of the waves is more than twice larger than that in the no wind shear case, reaching values of about $\pm 1.5 \mathrm{~K}$, the same order of magnitude that the waves observed (Tellmann et al., 2012). 
Above the convective layer, most of the waves propagate toward the west, significative of the obstacle effect wave, but there is also some waves propagating toward the east. In Earth studies, the vast majority of the waves generated by the obstacle propagate against the background wind (Fovell et al., 1992). For Venus, one possibility is that the ratio between the waves produced by the obstacle effect mechanism against the mechanical oscillator is closer to the equilibrium than the Earth, additional study is needed to understand this effect. The morphology of the wavefronts is also deeply impacted : wavefronts are linear in the wind-shear case in contrast to the circular wavefronts found in the no-wind shear case. Using the same methodology as in Section 3, we estimate that at $57 \mathrm{~km}$, the gravity waves have a typical horizontal wavelength of $10 \mathrm{~km}$. In presence of the wind shear, the vertical wavelength reaches more than $4 \mathrm{~km}$, very close to VeRa measurements (Tellmann et al. 2012 . The intrinsic frequency $\widehat{\omega}$ of the gravity waves at $57 \mathrm{~km}$ is of $5 \times 10^{-3} \mathrm{~s}^{-1}$. At $57 \mathrm{~km}$, the mean horizontal flow is about $67 \mathrm{~m} \mathrm{~s}^{-1}$ and the waves are advected with the flow, therefore the frequency $\omega$ is $3.6 \times 10^{-2} \mathrm{~s}^{-1}$. The corresponding group velocity is between $2.8 \mathrm{~m} \mathrm{~s}^{-1}$ on the vertical and $74 \mathrm{~m} \mathrm{~s}^{-1}$ on the horizontal. The direction of the wavefront is east-west, as is expected by the filtering exerted by the meridional component of the wind.
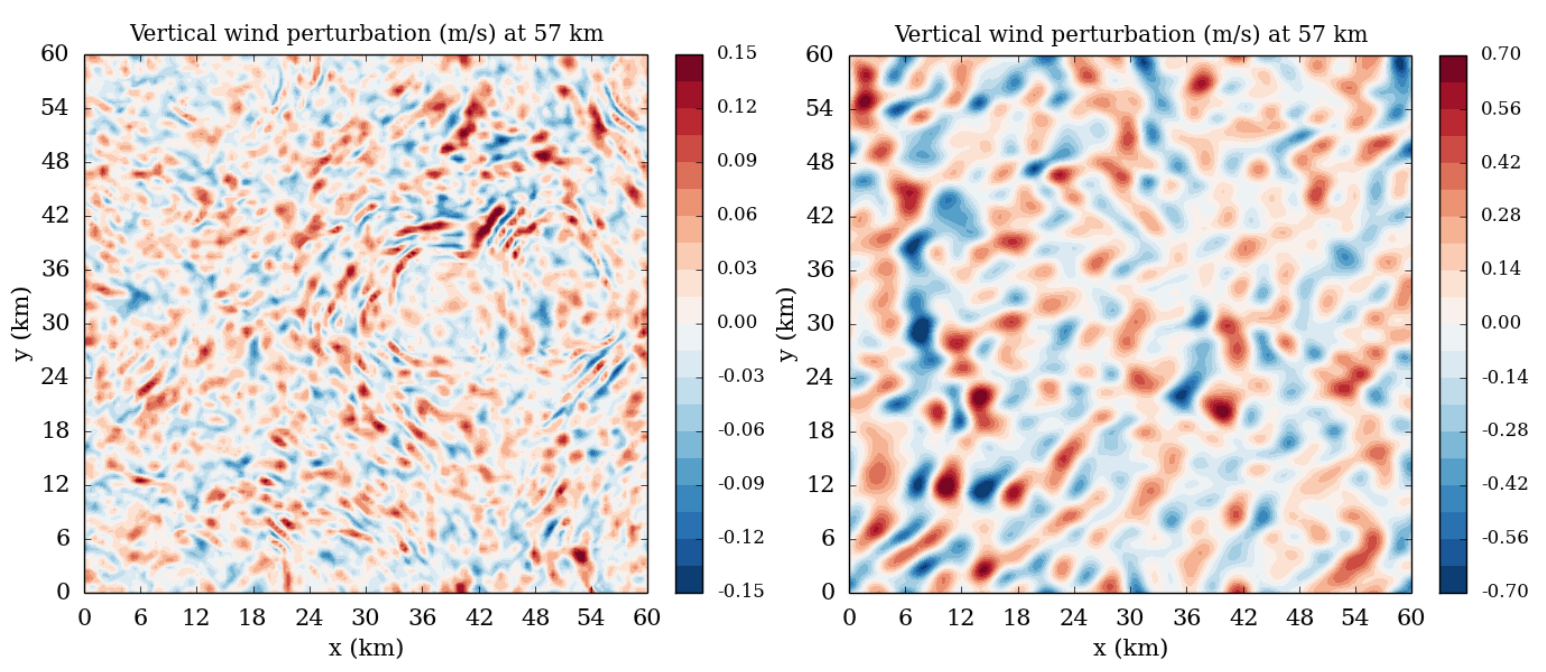

FIGURE 13 - Comparison of two snapshots of the vertical wind perturbation $\left(\mathrm{m} \mathrm{s}^{-1}\right)$ at the Equator at midnight without (left) and with (right) wind shear.

The wind shear also has a strong impact at higher altitude. Figure 14 shows a snapshots of the vertical wind perturbation $\left(\mathrm{m} \mathrm{s}^{-1}\right)$ at $70 \mathrm{~km}$ at the Equator at midnight in presence of wind shear. At this altitude, the gravity waves have a similar amplitude that as $57 \mathrm{~km}$ with also a linear wavefront but with greater wavelengths. The typical horizontal wavelength is of $20 \mathrm{~km}$, on the higher part of spectra of wavelength measured by VMC (Piccialli et al. 2014). The wave intrinsic frequency $\widehat{\omega}$ ranges from $1.910^{-3} \mathrm{~s}^{-1}$. At $70 \mathrm{~km}$, the mean horizontal wind velocity is approximately $106 \mathrm{~m} \mathrm{~s}^{-1}$. Therefore the frequency $\omega$ is $3.1 \times 10^{-2} \mathrm{~s}^{-1}$. The associated group velocity is on the vertical $1.2 \mathrm{~m} \mathrm{~s}^{-1}$ and on the horizontal $112 \mathrm{~m} \mathrm{~s}^{-1}$. The waves are advected with the flow, at $57 \mathrm{~km}$ the zonal is much stronger than the meridional wind (see Figure 10 therefore the direction of the phase propagation is east-west. At cloud top at high latitude, the zonal wind and meridional wind are close in amplitude, resulting to an horizontal wind more directed to the poles than at the Equator and thus a phase speed of the gravity wave more oriented towards the poles. This tendency of gravity waves to propagate towards 
the pole at mid-to-high latitudes is clearly observed in VMC observations (Piccialli et al., 2014).

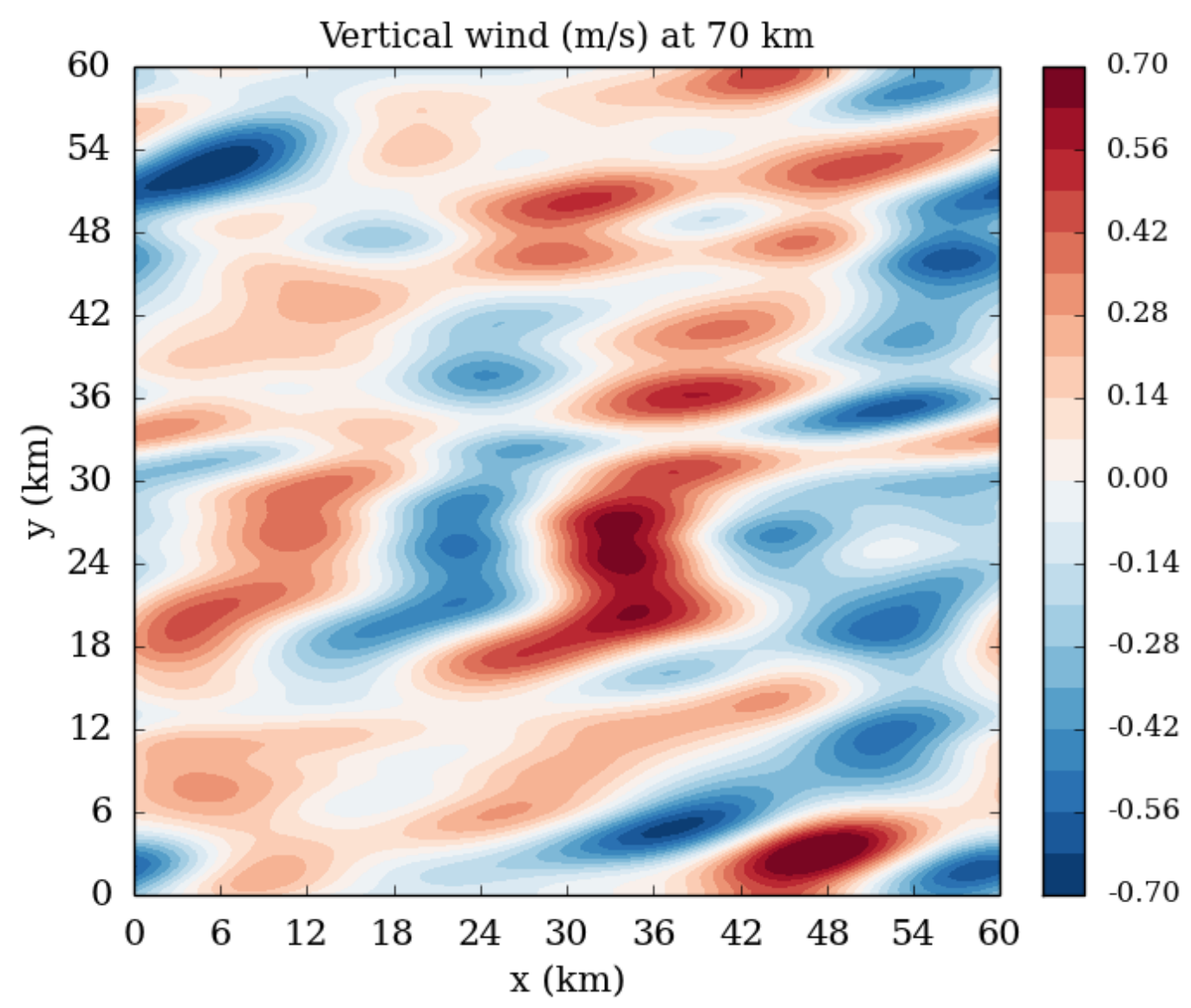

Figure 14 - Snapshots of the vertical wind perturbation $\left(\mathrm{m} \mathrm{s}^{-1}\right)$ at $70 \mathrm{~km}$ at the Equator at midnight in presence of wind shear.

To assess the impact of the gravity waves on the large-scale dynamical heating rate when they break, we evaluate the momentum transport with the Eliassen-Palm flux using the formalism of Andrews (1987) and Lott et al. (2012), we focus here on the vertical component of the flux $-\overline{\rho u^{\prime} w^{\prime}}$. Figure 15 shows the vertical angular momentum flux above and below the convective layer at the equator. The flux is strictly positive above the convective layer, while alternating between positive and negative values below. The vertical angular momentum flux reaches values of almost $3 \mathrm{mPa}$. At the altitude of the convective layer the density of the atmosphere of Venus is comparable to the density of the surface on Earth therefore we can compare the vertical momentum flux from gravity waves on the two planets. For Earth, convectively generated gravity waves momentum flux has been estimated with cloud-resolving model by (Horinouchi et al., 2002) at approximatively $0.2 \mathrm{mPa}$, an order of magnitude smaller.

The implementation of wind shear leads to the generation by the convection of more realistic gravity waves, compared to available observations. The calculation of the vertical angular momentum flux of these waves may be used to improve the GCM parameterization of the subgrid gravity waves based on Lott and Guez (2013) and recently used in the IPSL Venus GCM (Gilli et al., 2017). 

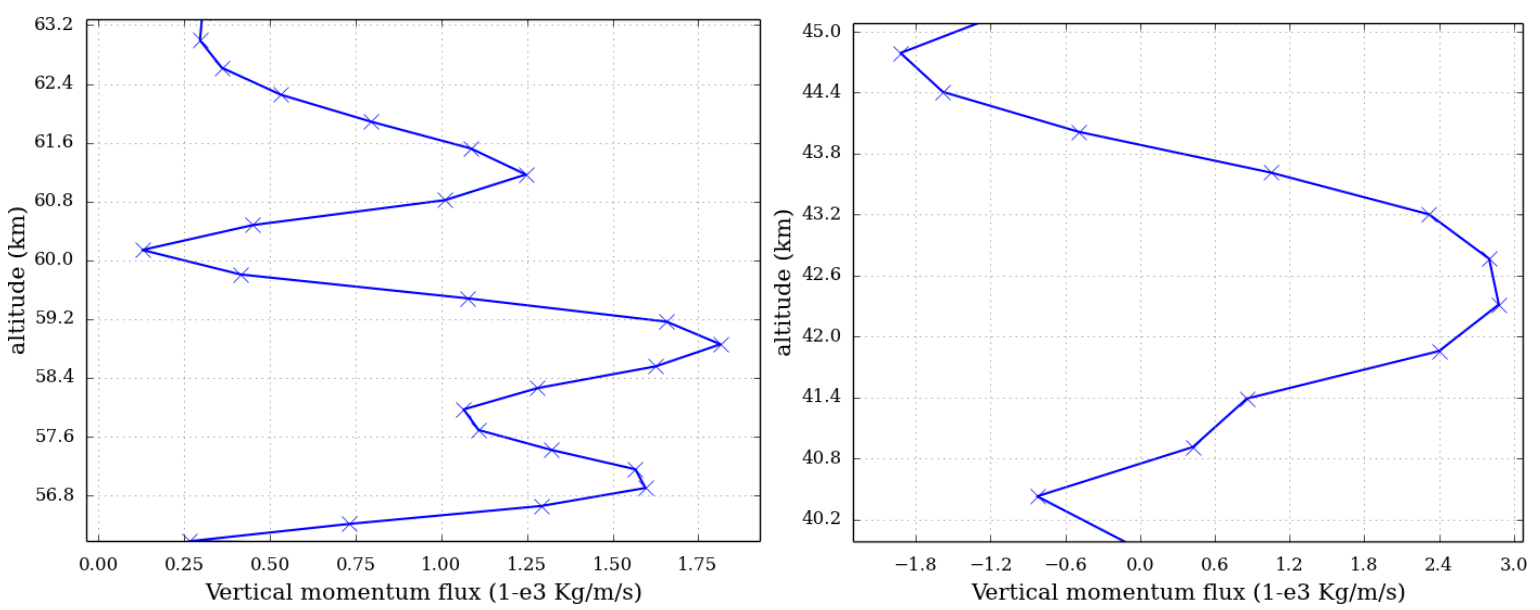

FIgURE 15 - Domain averaged vertical momentum flux ( $\mathrm{mPa}$ ) above (left) and below (right) the convective layer at the equator. 


\section{Dynamics at the top of the cloud}

Convective features near the equator at subsolar point have been observed by Pioneer Venus through the unknown UV-absorber (Rossow et al., 1980, Schubert et al., 1980), suggesting cellular structure of $10^{3} \mathrm{~km}$ width. Using as well the unknown UV-absorber, VMC/Venus Express observed convective structures at low latitude at the subsolar point, which were interpreted as cellular features of a diameter between tens of kilometers and few hundreds of kilometers (Markiewicz et al., 2007; Titov et al., 2012).

The figures shown below are without wind shear. Figure 16 shows the mean potential temperature and static stability between 63 and $75 \mathrm{~km}$ in our Venus LES run in equatorial conditions at noon. The presence of a zerostatic-stability layer indicates that the convection takes place between approximately 66.5 and $73.0 \mathrm{~km}$. This is in line with the convective features observed in the UV by Pioneer Venus and Venus Express. However, no mixed layer has been detected in radio-occultations at this altitude, neither by Magellan (Hinson and Jenkins, 1995), Venus Express (Tellmann et al. 2009) nor Akatsuki (Imamura et al., 2017). At this altitude, the atmosphere profiled by radio-occultations is very stable (the static stability is several Kelvin per kilometer).
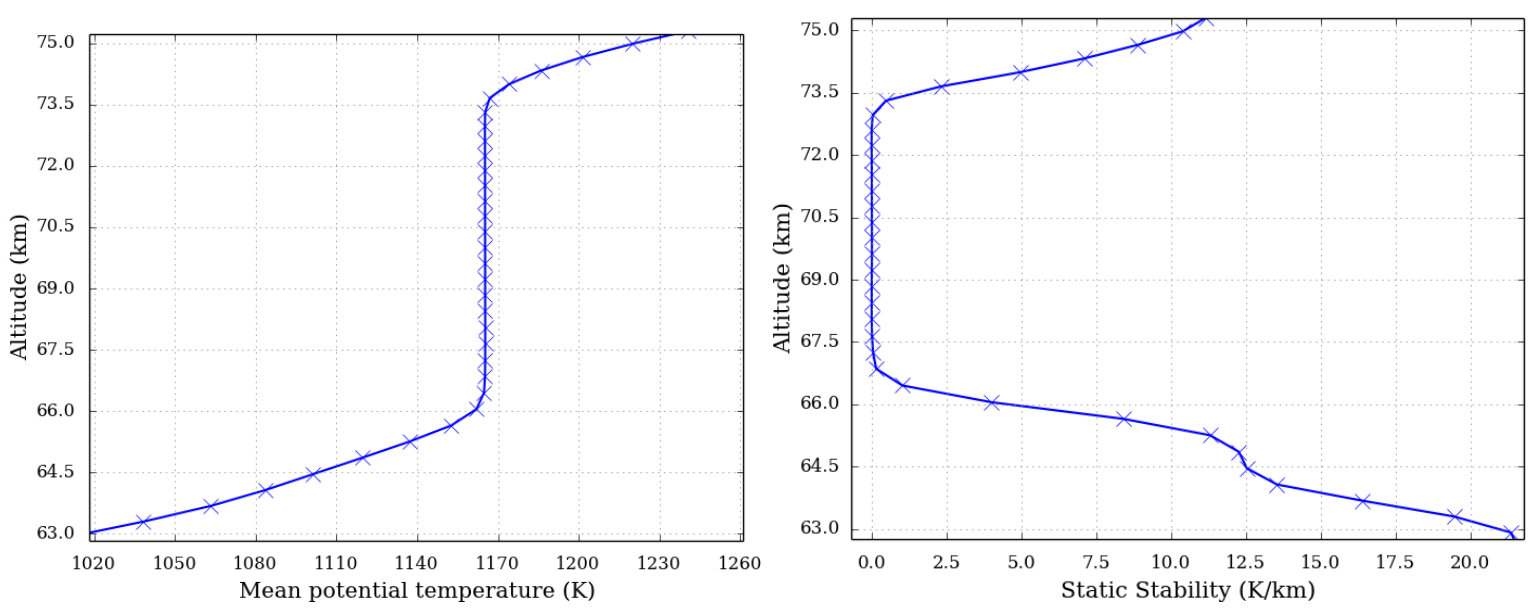

FIGURE 16 - Domain averaged vertical profile of potential temperature (K) (left) and static stability (K/km) (right) between 63 and $75 \mathrm{~km}$ at the equator at noon.

The convective motions that underlie the mixing layer in Figure 16 are shown in Figure 17, with two snapshots of : a vertical cross section in the middle of the domain and a horizontal cross section in the middle of the convective layer at $70 \mathrm{~km}$. The vertical wind ranges between 2.7 and $-3.5 \mathrm{~m} \mathrm{~s}^{-1}$. The convection is organized, similarly to the main cloud layer, as polygonal closed cells of diameter about 15 to $20 \mathrm{~km}$, consistent with the smallest cells observed in the Venus Express images (Markiewicz et al. 2007).

To understand the source behind this convective activity, we need to look at the heating rates (Fig 18). The bottom of the convective layer is located at the maximum of solar heating $(66 \mathrm{~km})$ creating a maximum positive value of the total heating rate. The top of the convection is located where the local maximum cooling of the IR heating rate (approximately $73 \mathrm{~km}$ ), as well as the large-scale dynamical heating rate, are creating a minimum negative value of the total heating rate. The heating resulting from the absorption of the solar flux by the unknown UV absorber destabilizes the atmosphere and initiates convective activity.

Figure 19 shows the vertical profile of the turbulent heat flux defined above. The behavior is similar to the 

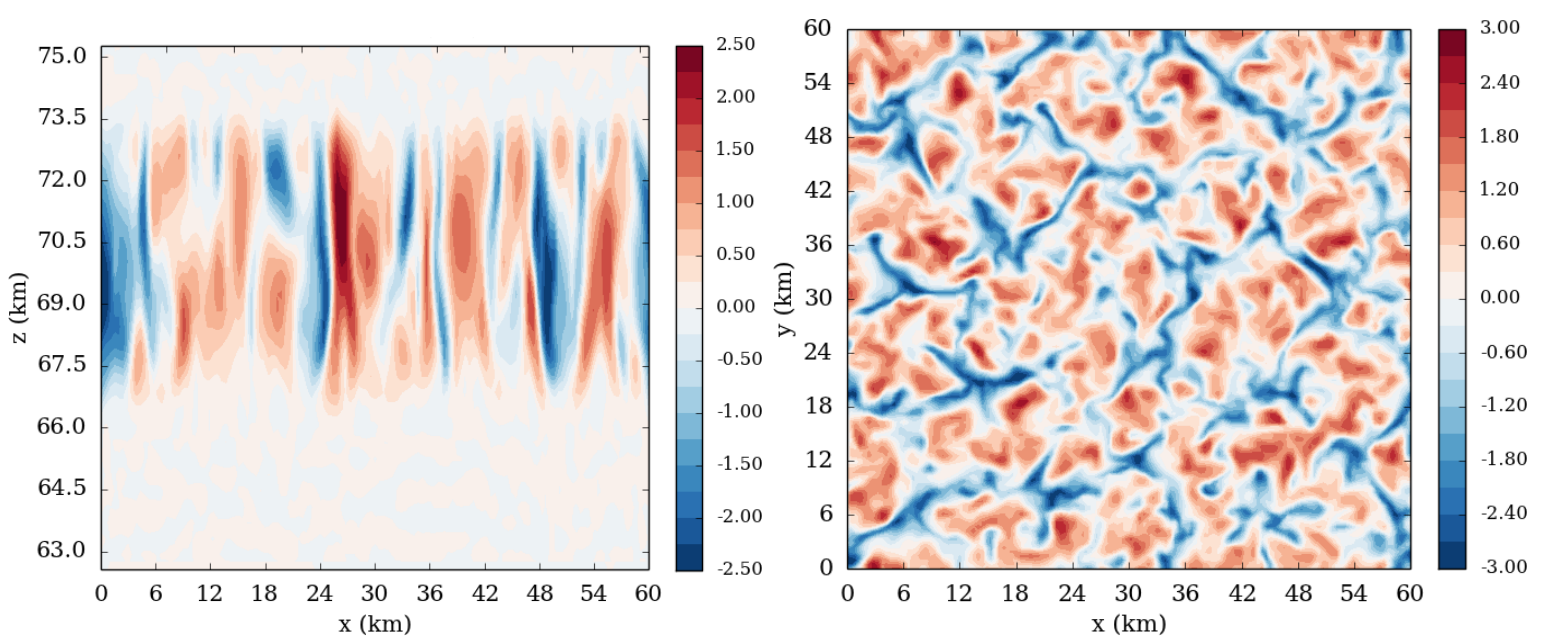

FIgURE 17 - Snapshots of the convective vertical motions : vertical cross-section at $\mathrm{y}=20 \mathrm{~km}$ between 63 and $75 \mathrm{~km}$ (left) and horizontal cross-section at $51 \mathrm{~km}$ of the vertical wind $\left(\mathrm{m} \mathrm{s}^{-1}\right)$ (right) for equatorial condition at noon.

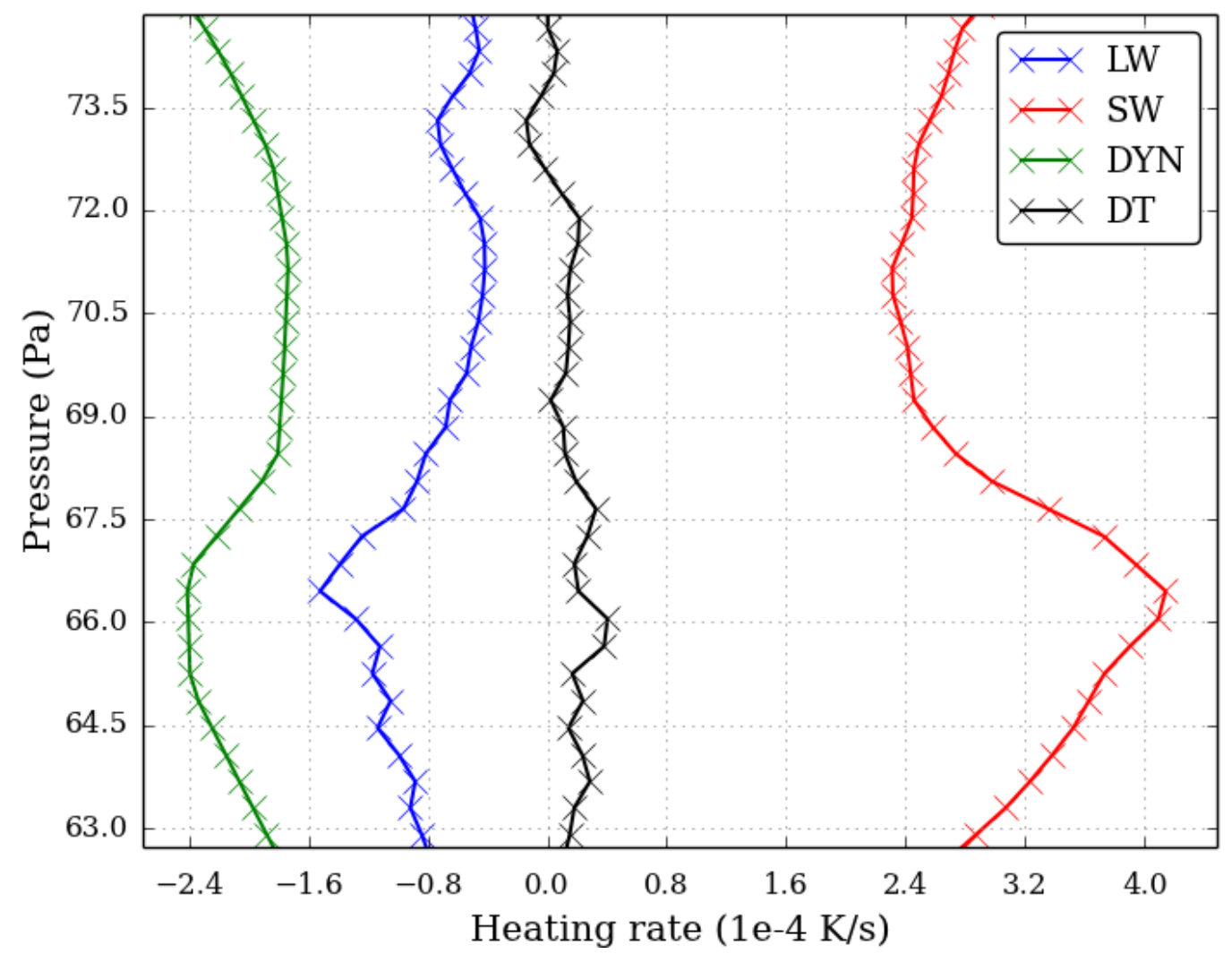

Figure 18 - Venus cloud top forcing : solar (SW), infrared (LW), dynamical (DYN) and total (DT) heating rates $(\mathrm{K} / \mathrm{s})$ between 63 and $75 \mathrm{~km}$ at the equator at noon.

convective layer below, with a mixing layer $(66.5$ to $73.3 \mathrm{~km})$ capped between an entrainment layer dominated downdraft-induced ones (65.6 to $66.5 \mathrm{~km}$ ) and an entrainment layer dominated by the updraft-induced ones (73.3 to $74.0 \mathrm{~km}$ ). Despite stronger vertical wind the cloud top convective heat flux is weaker than the convection below, because of the decrease with altitude of the density and heat capacity.

The gravity waves emitted by the cloud top convective activity are very similar to the ones emitted from the convective layer below. The amplitude of the waves is less than a Kelvin and the vertical wavelength is from 1 to $2 \mathrm{~km}$ and from 1 to $5 \mathrm{~km}$ for the horizontal wavelength. 


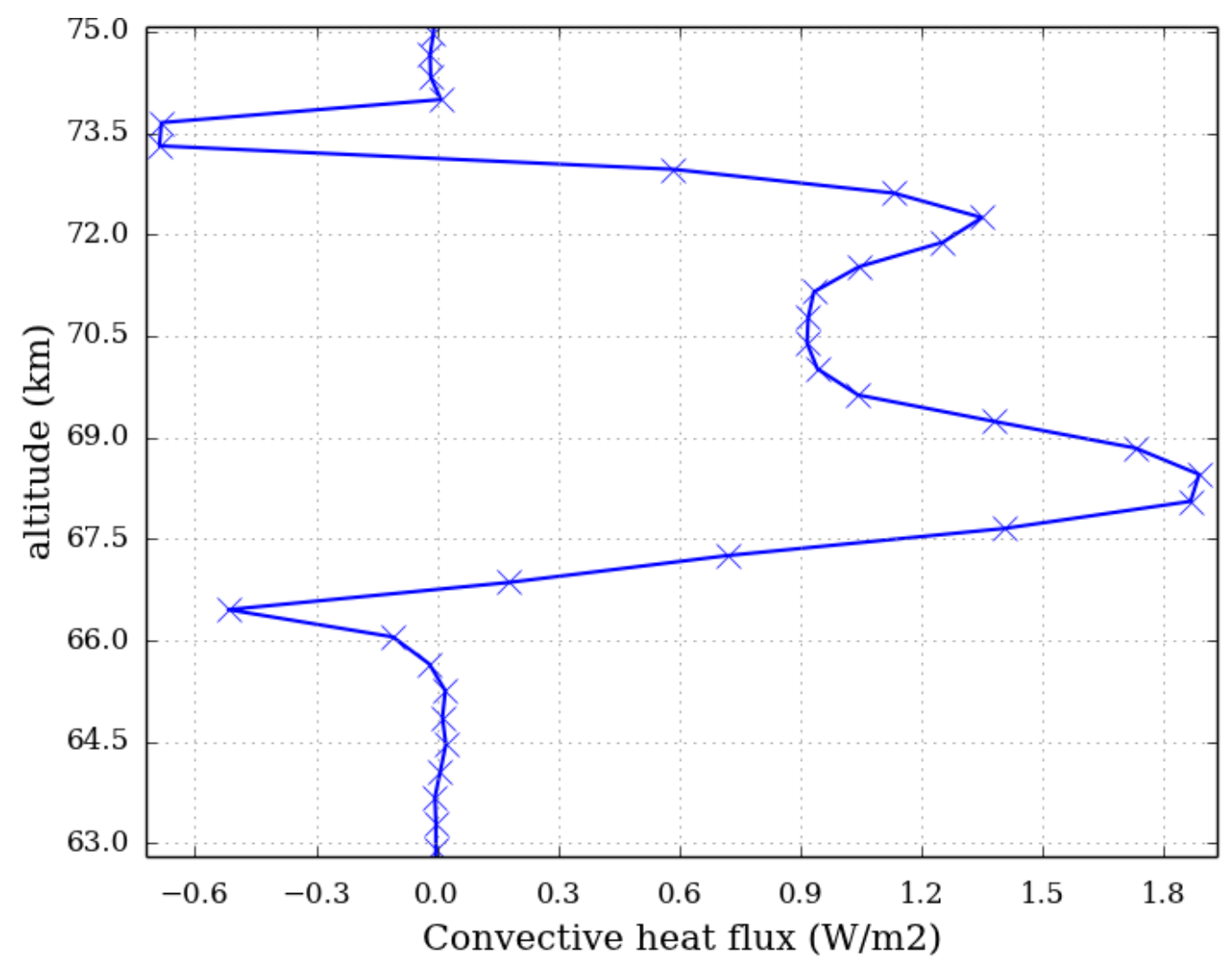

FIGURE 19 - Domain averaged vertical profile of the turbulent heat flux $\left(\mathrm{W} \mathrm{m}^{-2}\right)$ of the Venus cloud top convection between 63 and $75 \mathrm{~km}$ for equatorial condition at noon.

In Venus Express imaging observations, the convective activity at cloud top is present at low latitude close to the subsolar point. We can investigate this variability with local time and latitude with our Venus LES results. The comparison of the mean static stability in the $63-75 \mathrm{~km}$ at the Equator between midnight and noon is shown in Figure 20. The difference is clear between the two local times : at midnight the atmosphere is stable, with the exception of a layer of small static stability of few hundred meters where no convective plumes develop. The absence of heating by the sun inhibits the cloud top convection.

Figure 21 shows the comparison of the mean static stability at noon between the equator : $55^{\circ}$ and $75^{\circ}$ of latitude between 63 and $75 \mathrm{~km}$. There is a clear variability with latitude, the cloud-top convective layer present at the Equator is also present at $55^{\circ}$ latitude, while not present at all at $75^{\circ}$. The total heating rate at $75^{\circ}$ between 66 and $75 \mathrm{~km}$ has no clear-cut behavior and oscillates around zero, and therefore does not induce strong destabilization. This behavior is caused by the weaker solar heating and the large-scale dynamical heating rate, that is positive and negative in that region. At $55^{\circ}$ latitude, although weaker than at the Equator, the solar heating is still able to destabilize the atmosphere and enhance convection. However, the dynamics of the atmosphere is dominated at these altitudes by the equatorial jet and mid-latitude jets between 40 and $50^{\circ}$ latitude (Sánchez-Lavega et al., 2017). In the IPSL Venus GCM, the jets are reproduced (Garate-Lopez and Lebonnois, 2018) but the mid-latitude jet is located between 50 and $60^{\circ}$, poleward to the observed jet. Therefore, the large-scale dynamical heating rate at $55^{\circ}$ latitude may not be representative of the observed Venus environment at $55^{\circ}$ latitude while the IR and solar rates are realistic, so the comparison between the modeled and observed $55^{\circ}$ latitude cloud convective activity is difficult. Beyond the jets, at $65^{\circ}$ the large-scale 


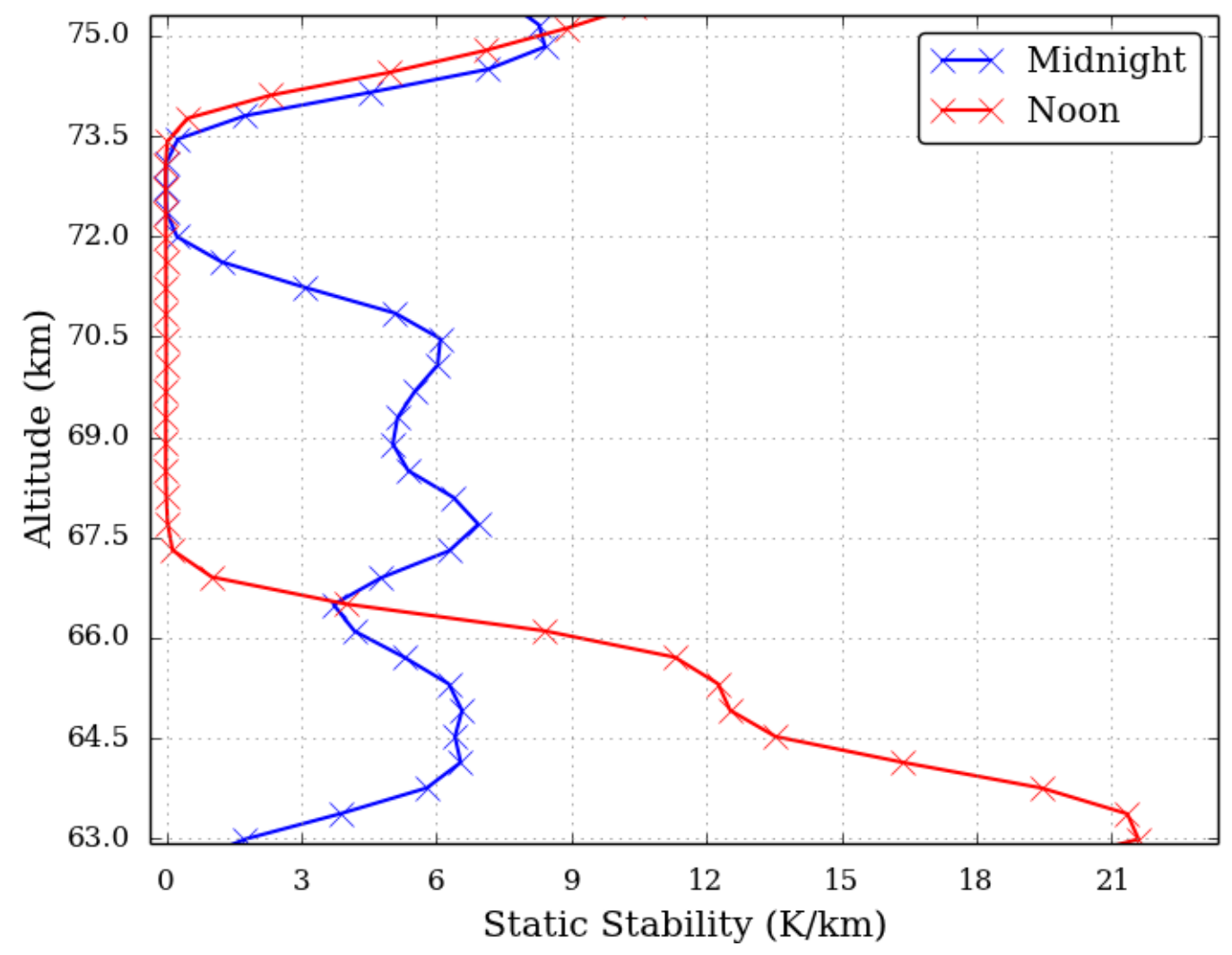

FIGURE 20 - Comparison of the domain averaged static stability vertical profile $(\mathrm{K} / \mathrm{km})$ for equatorial conditions at noon and at midnight between 63 and $75 \mathrm{~km}$.

dynamical heating rate (not shown here) at these altitudes has similar behavior as the $75^{\circ}$ case and does not induce cloud top convective activity.

To the extent of our knowledge, this is the first modeling of top-of-the-cloud convective activity. At noon the solar heating from the unknown UV absorber destabilizes the atmosphere and enhances convection. Observations of the cloud top at noon show convective activity only at low latitude while around $50^{\circ}$, the clouds are streaky, suggesting a laminar flow. In our model, we have convective activity at cloud top at both the Equator and $55^{\circ}$ latitude. The large-scale dynamical heating rate plays a role in inhibiting the convective activity. The unknown absorber being the source of this convective activity, the uncertainty about its abundance and optical properties used for the calculation of the solar heating rate (Haus et al. 2015) may affect the characteristics of the cloud top convective activity. Furthermore, the conundrum between, on the one hand, LES and imagery that hints at convective motions, and on the other hand, radio-occultations that indicate a very stable atmosphere, will have to be solved in future observational and modeling studies.

\section{Conclusion}

With the coupling of the WRF LES mode to the Venus LMD physics, we simulate a main convective layer that has characteristics close to the observations. Both the thickness of the main convective layer and the cell diameter, as well as the convective vertical winds, are consistent with measurements from past and ongoing missions. Using the LMD radiative scheme with a fine vertical resolution is needed to reproduce a 


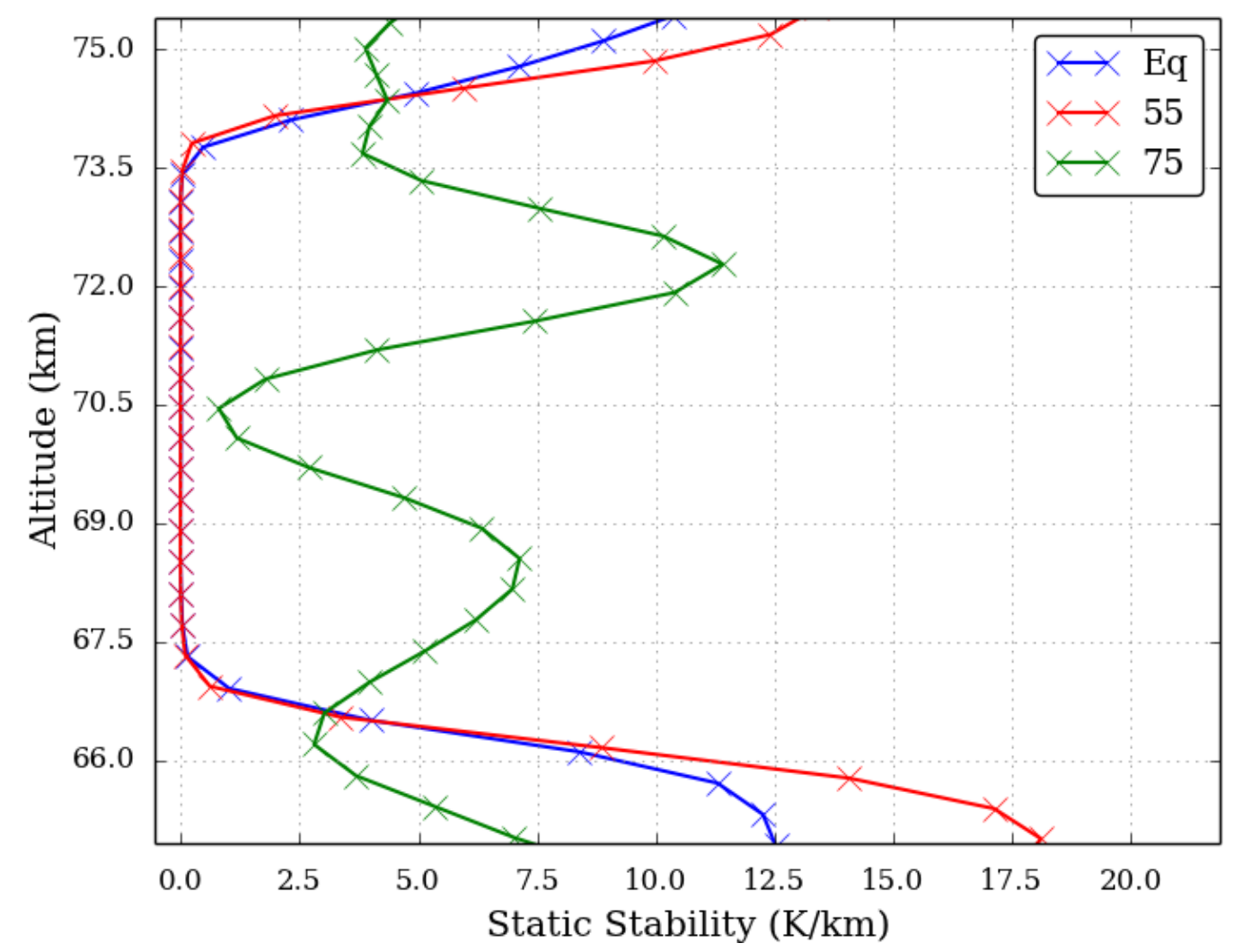

Figure 21 - Comparison of the domain averaged static stability vertical profile (K/km) at noon (LT $12 \mathrm{~h}$ ), for the Equator, $55^{\circ}$ latitude and $75^{\circ}$ latitude between 63 and $75 \mathrm{~km}$.

realistic convective layer. However, some discrepancies remain with observations. The variability with local time is hardly noticeable contrary to the first Akatsuki measurements. The variability with latitude is consistent with the VeRa observations for the Equator and $75^{\circ}$ but the $55^{\circ}$ latitude case is to close to the Equator case. As in the previous study, the large-scale dynamical heating is interpolated from the 50 GCM vertical levels to the 300 LES levels. Higher vertical resolution GCM runs could improve the large-scale dynamical heating rate. Changes in the dynamical core of the GCM should improve the angular momentum conservation and polar region modeling, and therefore the general circulation and the large-scale dynamical heating rate.

To improve the realistic aspect of the model, wind shear was taken into account. The effect on the convective layer is hardly noticeable whereas it is strong on the gravity waves. In addition to mechanical oscillator mechanism, the obstacle effect wave mechanism is now present. This additional wave production mechanism has the effect to generate gravity waves with higher amplitude. The horizontal wavelengths are also higher and closer to the observations. This process has to be taken into account to model properly the gravity waves associated with the convective activity.

The vertical extension of the model made it possible to study the cloud-top cell features observed at low latitude at the subsolar point. The solar heating from the unknown UV absorber destabilizes the atmosphere and our model predicts convective activity of about $6 \mathrm{~km}$ in the vertical that could be at the origin of these observed cell features. However, none of the radio occulation experiments observed a mixed layer at the altitude; a very stable atmosphere is observed. Convective activity at $55^{\circ}$ latitude is also obtained in our simulations, though only streaky clouds are observed at these latitudes. Possible explanations for this discrepancy include 
the distribution of the unknown UV absorber as well as discrepancy in the large-scale dynamical heating rate, that is not fully representative of the actual $55^{\circ}$ latitude environment in the IPSL Venus GCM simulations.

Our model is now able to reproduce realistic cloud convective activity and associated gravity waves, and is a tool to interpret the observations of the subsolar convective activity. Coupled with the photochemistry and microphysical schemes of the IPSL Venus GCM, the present model could investigate the impact of the mesoscale dynamics on the cloud formation and variability.

\section{Acknowledgements}

The authors acknowledge financial support from Centre National d'Études Spatiales (CNES) and Programme National de Planétologie (PNP). Simulations were performed at CINES, France, under the project $n^{\circ} 1116$ and at Sorbonne Université with HPCaVe. We would like to thank Dr. Takeshi Horinouchi and the second anonymous reviewer for their reviews that help improve the paper. Simulation results used to obtain the figures in this paper are available in the open online repository https://figshare.com/s/03a0497e6537dbbca4ba. Full simulation results performed in this paper are available upon reasonable request (contact : maxence.lefevre@lmd.jussieu.fr).

\section{Références}

Ando, H., Imamura, T., Tsuda, T., Tellmann, S., Pätzold, M., and Häusler, B. (2015). Vertical Wavenumber Spectra of Gravity Waves in the Venus Atmosphere Obtained fromVenus ExpressRadio Occultation Data : Evidence for Saturation. Journal of Atmospheric Sciences, 72 :2318-2329.

Andrews, D. G. (1987). On the interpretation of the Eliassen-palm flux divergence. Quarterly Journal of the

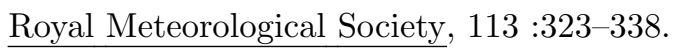

Ansong, J. K. and Sutherland, B. R. (2010). Internal gravity waves generated by convective plumes. Journal of Fluid Mechanics, 648 :405.

Atkinson, B. W. and Wu Zhang, J. (1996). Mesoscale shallow convection in the atmosphere. Reviews of Geophysics, $34: 403-431$.

Baker, R. D., Schubert, G., and Jones, P. W. (1998). Cloud-Level Penetrative Compressible Convection in the Venus Atmosphere. J. of Atm. Sc., 55 :3-18.

Baker, R. D., Schubert, G., and Jones, P. W. (2000a). Convectively generated internal gravity waves in the lower atmosphere of Venus. I. No wind shear. J. of Atm. Sc., 57 :184-199.

Baker, R. D., Schubert, G., and Jones, P. W. (2000b). Convectively generated internal gravity waves in the lower atmosphere of Venus. II. Mean wind shear and wave-mean flow interaction. J. of Atm. Sc., 57 :200-215. 
Barstow, J. K., Tsang, C. C. C., Wilson, C. F., Irwin, P. G. J., Taylor, F. W., McGouldrick, K., Drossart, P., Piccioni, G., and Tellmann, S. (2012). Models of the global cloud structure on Venus derived from Venus Express observations. Icarus, $217: 542-560$.

Belton, M. J. S., Smith, G. R., Schubert, G., and del Genio, A. D. (1976). Cloud patterns, waves and convection in the Venus atmosphere. Journal of Atmospheric Sciences, 33 :1394-1417.

Cimino, J. (1982). The composition and vertical structure of the lower cloud deck on Venus. Icarus, 51 :334-357.

Clark, T. L., Hauf, T., and Kuettner, J. P. (1986). Convectively forced internal gravity waves : Results from two-dimensional numerical experiments. Quarterly Journal of the Royal Meteorological Society, 112:899-925.

Counselman, C. C., Gourevitch, S. A., King, R. W., Loriot, G. B., and Ginsberg, E. S. (1980). Zonal and meridional circulation of the lower atmosphere of Venus determined by radio interferometry. Journal of Geophysical Research, 85 :8026-8030.

Deardorff, J. W. (1972). Numerical Investigation of Neutral and Unstable Planetary Boundary Layers. Journal of Atmospheric Sciences, $29: 91-115$.

Eymet, V., Fournier, R., Dufresne, J.-L., Lebonnois, S., Hourdin, F., and Bullock, M. A. (2009). Net exchange parameterization of thermal infrared radiative transfer in Venus' atmosphere. J. of Geophys. Res. (Planets), $114:$ E11008.

Fovell, R., Durran, D., and Holton, J. R. (1992). Numerical Simulations of Convectively Generated Stratospheric Gravity Waves. Journal of Atmospheric Sciences, 49 :1427-1442.

Frits, D. C. and Alexander, M. J. (2003). Gravity wave dynamics and effects in the middle atmosphere. Rev. of. Geoph., 41 :1112-1131.

Garate-Lopez, I. and Lebonnois, S. (2018). Latitudinal Variation of Clouds' Structure Responsible for Venus' Cold Collar. Icarus.

Gierasch, P. J., Goody, R. M., Young, R. E., Crisp, D., Edwards, C., Kahn, R., Rider, D., del Genio, A., Greeley, R., Hou, A., Leovy, C. B., McCleese, D., and Newman, M. (1997). The General Circulation of the Venus Atmosphere : an Assessment. In Venus II : Geology, Geophysics, Atmosphere, and Solar Wind Environment, page 459 .

Gilli, G., Lebonnois, S., González-Galindo, F., López-Valverde, M. A., Stolzenbach, A., Lefèvre, F., Chaufray, J. Y., and Lott, F. (2017). Thermal structure of the upper atmosphere of Venus simulated by a ground-tothermosphere GCM. Icarus, $281: 55-72$.

Haus, R., Kappel, D., and Arnold, G. (2014). Atmospheric thermal structure and cloud features in the southern hemisphere of Venus as retrieved from VIRTIS/VEX radiation measurements. Icarus, 232 :232-248. 
Haus, R., Kappel, D., and Arnold, G. (2015). Radiative heating and cooling in the middle and lower atmosphere of Venus and responses to atmospheric and spectroscopic parameter variations. Planetary and Space Science, $117: 262-294$.

Hinson, D. P. and Jenkins, J. M. (1995). Magellan radio occultation measurements of atmospheric waves on Venus. Icarus, $114: 310-327$.

Horinouchi, T. (2004). Simulated breaking of convectively generated mesoscale gravity waves and airglow modulation. Journal of Atmospheric and Solar-Terrestrial Physics, 66 :755-767.

Horinouchi, T., Nakamura, T., and Kosaka, J.-i. (2002). Convectively generated mesoscale gravity waves simulated throughout the middle atmosphere. Geophysical Research Letters, $29: 2007$.

Imamura, T., Ando, H., Tellmann, S., Pätzold, M., Häusler, B., Yamazaki, A., Sato, T. M., Noguchi, K., Futaana, Y., Oschlisniok, J., Limaye, S., Choudhary, R. K., Murata, Y., Takeuchi, H., Hirose, C., Ichikawa, T., Toda, T., Tomiki, A., Abe, T., Yamamoto, Z.-i., Noda, H., Iwata, T., Murakami, S.-y., Satoh, T., Fukuhara, T., Ogohara, K., Sugiyama, K.-i., Kashimura, H., Ohtsuki, S., Takagi, S., Yamamoto, Y., Hirata, N., Hashimoto, G. L., Yamada, M., Suzuki, M., Ishii, N., Hayashiyama, T., Lee, Y. J., and Nakamura, M. (2017). Initial performance of the radio occultation experiment in the Venus orbiter mission Akatsuki. Earth, Planets, and Space, $69: 137$.

Imamura, T., Higuchi, T., Maejima, Y., Takagi, M., Sugimoto, N., Ikeda, K., and Ando, H. (2014). Inverse insolation dependence of Venus' cloud-level convection. Icarus, 228 :181-188.

Kerzhanovich, V. V., Aleksandrov, Y. N., Andreev, R. A., Armand, N. A., Bakitko, R. V., Blamont, J. E., Boloh, L., Hildebrand, C. E., Ignatov, S. P., Ingersoll, A. P., Lysov, V. P., Mottsulev, B. I., Petit, G., Pichkhadze, K. M., Preston, R. A., Vorontsov, V. A., Vyshlov, A. S., Young, R. E., and Zaitsev, A. L. (1986). Smallscale Turbulence in the Venus Middle Cloud Layer. Soviet Astronomy Letters, 12 :20-22.

Lebonnois, S., Hourdin, F., Eymet, V., Crespin, A., Fournier, R., and Forget, F. (2010). Superrotation of Venus' atmosphere analyzed with a full general circulation model. J. of Geophys. Res. (Planets), 115 :E06006.

Lebonnois, S., Sugimoto, N., and Gilli, G. (2016). Wave analysis in the atmosphere of Venus below 100-km altitude, simulated by the LMD Venus GCM. Icarus, $278: 38-51$.

Lefèvre, M., Spiga, A., and Lebonnois, S. (2017). Three-dimensional turbulence-resolving modeling of the Venusian cloud layer and induced gravity waves. Journal of Geophysical Research (Planets), 122 :134-149.

Lilly, D. K. (1962). On the numerical simulation of buoyant convection. Tellus, 14(2) :148-172.

Linkin, V. M., Kerzhanovich, V. V., Lipatov, A. N., Pichkadze, K. M., Shurupov, A. A., Terterashvili, A. V., Ingersoll, A. P., Crisp, D., Grossman, A. W., Young, R. E., Seiff, A., Ragent, B., Blamont, J. E., Elson, L. S., and Preston, R. A. (1986). VEGA balloon dynamics and vertical winds in the Venus middle cloud region. Science, $231: 1417-1419$. 
Lott, F. and Guez, L. (2013). A stochastic parameterization of the gravity waves due to convection and its impact on the equatorial stratosphere. Journal of Geophysical Research (Atmospheres), 118 :8897-8909.

Lott, F., Guez, L., and Maury, P. (2012). A stochastic parameterization of non-orographic gravity waves : Formalism and impact on the equatorial stratosphere. Geophysical Research Letters, 39 :L06807.

Markiewicz, W. J., Titov, D. V., Limaye, S. S., Keller, H. U., Ignatiev, N., Jaumann, R., Thomas, N., Michalik, H., Moissl, R., and Russo, P. (2007). Morphology and dynamics of the upper cloud layer of Venus. Nature, $450: 633-636$.

Mason, P. J. and Sykes, R. I. (1982). A two-dimensional numerical study of horizontal roll vortices in an inversion capped planetary boundary layer. Quarterly Journal of the Royal Meteorological Society, 108:801-823.

McGouldrick, K. and Toon, O. B. (2008). Observable effects of convection and gravity waves on the Venus condensational cloud. Plan. and Sp. Sci., 56 :1112-1131.

Moeng, C., Dudhia, J., Klemp, J., and Sullivan, P. (2007). Examining Two-Way Grid Nesting for Large Eddy Simulation of the PBL Using the WRF Model. Monthly Weather Review, 135(6) :2295-2311.

Peralta, J., Hueso, R., Sánchez-Lavega, A., Piccioni, G., Lanciano, O., and Drossart, P. (2008). Characterization of mesoscale gravity waves in the upper and lower clouds of Venus from VEX-VIRTIS images. J. of Geophys.

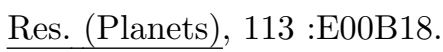

Piccialli, A., Titov, D. V., Sánchez-Lavega, A., Peralta, J., Shalygina, O., Markiewicz, W. J., and Svedhem, H. (2014). High latitude gravity waves at the Venus cloud tops as observed by the Venus Monitoring Camera on board Venus Express. Icarus, $227: 94-111$.

Rossow, W. B., del Genio, A. D., Limaye, S. S., and Travis, L. D. (1980). Cloud morphology and motions from Pioneer Venus images. Journal of Geophysical Research, 85 :8107-8128.

Sánchez-Lavega, A., Lebonnois, S., Imamura, T., Read, P., and Luz, D. (2017). The Atmospheric Dynamics of Venus. Space Science Review, 212 :1541-1616.

Schubert, G., Covey, C., del Genio, A., Elson, L. S., Keating, G., Seiff, A., Young, R. E., Apt, J., Counselman, C. C., Kliore, A. J., Limaye, S. S., Revercomb, H. E., Sromovsky, L. A., Suomi, V. E., Taylor, F., Woo, R., and von Zahn, U. (1980). Structure and circulation of the Venus atmosphere. Journal of Geophysical $\underline{\text { Research, }} 85$ :8007-8025.

Seiff, A., Kirk, D. B., Young, R. E., Blanchard, R. C., Findlay, J. T., Kelly, G. M., and Sommer, S. C. (1980). Measurements of thermal structure and thermal contrasts in the atmosphere of Venus and related dynamical observations - Results from the four Pioneer Venus probes. Journal of Geophysical Research, 85 :7903-7933.

Skamarock, W. C. and Klemp, J. B. (2008). A time-split nonhydrostatic atmospheric model for weather research and forecasting applications. Journal of Computational Physics, 227 :3465-3485. 
Spiga, A., Barth, E., Gu, Z., Hoffmann, F., Ito, J., Jemmett-Smith, B., Klose, M., Nishizawa, S., Raasch, S., Rafkin, S., Takemi, T., Tyler, D., and Wei, W. (2016). Large-Eddy Simulations of Dust Devils and Convective Vortices. Space Science Reviews, $203: 245-275$.

Spiga, A., Forget, F., Lewis, S. R., and Hinson, D. P. (2010). Structure and dynamics of the convective boundary layer on mars as inferred from large-eddy simulations and remote-sensing measurements. Quarterly Journal of the Royal Meteorological Society, $136: 414-428$.

Sullivan, P. P. and Patton, E. G. (2011). The Effect of Mesh Resolution on Convective Boundary Layer Statistics and Structures Generated by Large-Eddy Simulation. Journal of Atmospheric Sciences, 68 :2395-2415.

Tellmann, S., Haeusler, B., Paetzold, M., Bird, M. K., Tyler, G. L., Andert, T., and Remus, S. (2009). The Structure of the Venus Neutral Atmosphere as seen by the Radio Science Experiment VeRa on Venus Express. J. of Geophys. Res. (Planets), 114 :E00B36.

Tellmann, S., Häusler, B., Hinson, D. P., Tyler, G. L., Andert, T. P., Bird, M. K., Imamura, T., Pätzold, M., and Remus, S. (2012). Small-scale temperature fluctuations seen by the VeRa Radio Science Experiment on Venus Express. Icarus, $221: 471-480$.

Titov, D. V., Markiewicz, W. J., Ignatiev, N. I., Song, L., Limaye, S. S., Sánchez-Lavega, A., Hesemann, J., Almeida, M., Roatsch, T., Matz, K.-D., Scholten, F., Crisp, D., Esposito, L. W., Hviid, S. F., Jaumann, R., Keller, H. U., and Moissl, R. (2012). Morphology of the cloud tops as observed by the Venus Express Monitoring Camera. Icarus, 217 :682-701.

Torrence, C. and Compo, G. P. (1998). A practical guide to wavelet analysis. Bulletin of the American Meteorological Society, $79: 61-78$.

Yamamoto, M. (2011). Microscale simulations of Venus convective adjustment and mixing near the surface : Thermal and material transport processes. Icarus, 211 :993-1006.

Yamamoto, M. (2014). Idealized numerical experiments on microscale eddies in the Venusian cloud layer. Earth, Planets, and Space, $66: 27$. 